\title{
The high Arctic in extreme winters: vortex, temperature, and MLS and ACE-FTS trace gas evolution
}

\author{
G. L. Manney ${ }^{1,2}$, W. H. Daffer ${ }^{3}$, K. B. Strawbridge ${ }^{4}$, K. A. Walker ${ }^{5,6}$, C. D. Boone ${ }^{6}$, P. F. Bernath ${ }^{7,6}$, \\ T. Kerzenmacher ${ }^{5}$, M. J. Schwartz ${ }^{1}$, K. Strong ${ }^{5}$, R. J. Sica ${ }^{8}$, K. Krüger ${ }^{9}$, H. C. Pumphrey ${ }^{10}$, A. Lambert ${ }^{1}$, \\ M. L. Santee ${ }^{1}$, N. J. Livesey $^{1}$, E. E. Remsberg ${ }^{11}$, M. G. Mlynczak ${ }^{11}$, and J. R. Russell III ${ }^{12}$ \\ ${ }^{1}$ Jet Propulsion Laboratory, California Institute of Technology, Pasadena, CA, USA \\ ${ }^{2}$ Department of Physics, New Mexico Institute of Mining and Technology, Socorro, NM, USA \\ ${ }^{3}$ Columbus Technologies Inc., Pasadena, CA, USA \\ ${ }^{4}$ Science and Technology Branch, Environment Canada, Ontario, Canada \\ ${ }^{5}$ Department of Physics, University of Toronto, Toronto, Ontario, Canada \\ ${ }^{6}$ Department of Chemistry, University of Waterloo, Waterloo, Ontario, Canada \\ ${ }^{7}$ Department of Chemistry, University of York, Heslington, York, UK \\ ${ }^{8}$ Department of Physics and Astronomy, The University of Western Ontario, London, Ontario, Canada \\ ${ }^{9}$ Leibniz-Institute for Marine Sciences at Kiel University (IFM-GEOMAR), Kiel, Germany \\ ${ }^{10}$ School of Geosciences, University of Edinburgh, Edinburgh, UK \\ ${ }^{11}$ NASA Langley Research Center, Hampton, VA, USA \\ ${ }^{12}$ Atmospheric and Planetary Sciences, Hampton University, Hampton, VA, USA
}

Received: 21 June 2007 - Published in Atmos. Chem. Phys. Discuss.: 17 July 2007

Revised: 28 November 2007 - Accepted: 11 December 2007 - Published: 6 February 2008

\begin{abstract}
The first three Arctic winters of the ACE mission represented two extremes of winter variability: Stratospheric sudden warmings (SSWs) in 2004 and 2006 were among the strongest, most prolonged on record; 2005 was a record cold winter. Canadian Arctic Atmospheric Chemistry Experiment (ACE) Validation Campaigns were conducted at Eureka $\left(80^{\circ} \mathrm{N}, 86^{\circ} \mathrm{W}\right)$ during each of these winters. New satellite measurements from ACE-Fourier Transform Spectrometer (ACE-FTS), Sounding of the Atmosphere using Broadband Emission Radiometry (SABER), and Aura Microwave Limb Sounder (MLS), along with meteorological analyses and Eureka lidar temperatures, are used to detail the meteorology in these winters, to demonstrate its influence on transport, and to provide a context for interpretation of ACE-FTS and validation campaign observations. During the 2004 and 2006 SSWs, the vortex broke down throughout the stratosphere, reformed quickly in the upper stratosphere, and remained weak in the middle and lower stratosphere. The stratopause reformed at very high altitude, near $75 \mathrm{~km}$. ACE measurements covered both vortex and extra-vortex conditions in each winter, except in late-February through midMarch 2004 and 2006, when the strong, pole-centered vortex that reformed after the SSWs resulted in ACE sampling only inside the vortex in the middle through upper strato-
\end{abstract}

Correspondence to: G. L. Manney

(manney@mls.jpl.nasa.gov) sphere. The 2004 and 2006 Eureka campaigns were during the recovery from the SSWs, with the redeveloping vortex over Eureka. 2005 was the coldest winter on record in the lower stratosphere, but with an early final warming in midMarch. The vortex was over Eureka at the start of the 2005 campaign, but moved away as it broke up. Disparate temperature profile structure and vortex evolution resulted in much lower (higher) temperatures in the upper (lower) stratosphere in 2004 and 2006 than in 2005. Satellite temperatures agree well with lidar data up to 50-60 km, and ACE-FTS, MLS and SABER show good agreement in high-latitude temperatures throughout the winters. Consistent with a strong, cold upper stratospheric vortex and enhanced radiative cooling after the SSWs, MLS and ACE-FTS trace gas measurements show strongly enhanced descent in the upper stratospheric vortex in late January through March 2006 compared to that in 2005 .

\section{Introduction}

The Atmospheric Chemistry Experiment (ACE) has been providing daily atmospheric measurements, with a particular focus on the polar winter middle atmosphere, since early 2004 (Bernath et al., 2005). The Canadian Arctic ACE Validation Campaigns (herein called Eureka campaigns) comprise an extensive set of ground-based measurements at

Published by Copernicus Publications on behalf of the European Geosciences Union. 
the Polar Environment Atmospheric Research Laboratory (PEARL - formerly Environment Canada's Arctic Stratospheric Ozone AStrO Observatory) at Eureka Nunavut $\left(80^{\circ} \mathrm{N}, 86^{\circ} \mathrm{W}\right)$ during each late winter since the launch of ACE e.g., Walker et al., 2005; Kerzenmacher et al., 2005; Fraser et al., 2007; Sung et al., 2007a, Sung et al. $\left(2007 b^{1}\right)$; Fu et al., 2008². Data from the 2004 through 2006 campaigns are currently available and being used extensively for ACE validation. Together with the ACE-Fourier Transform Spectrometer (ACE-FTS), measurements from the Sounding of the Atmosphere using Broadband Emission Radiometry (SABER, since early 2002) and Aura Microwave Limb Sounder (MLS, since August 2004) instruments provide an unprecedented wealth of temperature and trace gas data covering the upper troposphere through the mesosphere for several years, enough to begin providing important advances in our ability to examine seasonal and interannual variability in meteorological conditions, transport and chemistry.

The first three winters of the ACE mission (2003-2004, 2004-2005, and 2005-2006) provide an ideal "laboratory" for examining the extremes of Arctic winter middle atmosphere variability, including the effects of unusual meteorological conditions on transport and chemistry. A "major" stratospheric sudden warming (SSW) beginning in late December 2003 was the most prolonged on record (Manney et al., 2005); it was followed by recovery to an unusually strong vortex in the upper stratosphere, while the middle and lower stratospheric vortices remained very weak for the rest of the winter; the final warming was unusually late (Manney et al., 2005). The 2004-2005 winter was the coldest on record in the lower stratosphere (e.g., Manney et al., 2006b), with arguably the most chemical ozone $\left(\mathrm{O}_{3}\right)$ loss ever recorded in the Arctic (WMO, 2007, and references therein); the winter ended early in a major final warming. The 2005-2006 winter was similar in many ways to the 2003-2004 winter, with a very strong, prolonged major SSW beginning in early to mid January, a rapid recovery to an unusually strong vortex in the upper stratosphere while the lower and middle stratospheric vortices remained weak, and a very late final warming (e.g., Braathen et al., 2006; WMO, 2007; Hoffmann et al., 2007), Manney et al.(2007) ${ }^{3}$

1 Sung, K., Strong, K., Mittermeier, R. L., et al.: Groundbased column measurements at Eureka, Nunavut made using two Fourier transform infrared spectrometers in spring 2004 and 2005, and comparisons with the Atmospheric Chemistry Experiment, Atmos. Chem. Phys., to be submitted, 2007b.

${ }^{2} \mathrm{Fu}$, D., Walker, K. A., Mittermeier, R., Strong, K., Sung, K., Fast, H., Bernath, P. F., Boone, C. D., Daffer, W. H., Fogal, P., Kolonjari, F., Loewen, P., Manney, G. L., and Mikhailov, O.: Simultaneous atmospheric measurements using two Fourier transform infrared spectrometers at the Polar Environment Atmospheric Research Laboratory during spring 2006, and comparisons with the Atmospheric Chemistry Experiment-Fourier Transform Spectrometer, Atmos. Chem. Phys. Discuss., in review, 2008.

${ }^{3}$ Manney, G. L., Krüger, K., Pawson, S., Minschwaner, K.,
These three winters thus cover the extremes of recorded interannual variability during Arctic winter, and the ACE-FTS, MLS, and SABER data allow us to study them in a detail never before possible. The Eureka campaigns provide additional data for focusing in on local variations, including high-resolution lidar temperature data, and for intercomparison with and validation of the satellite data.

In the following, we use the global daily temperature and trace gas data from MLS and SABER, ACE-FTS data, and gridded meteorological analyses from operational assimilation systems to contrast the meteorology of the upper troposphere through lower mesosphere in these winters. We focus on the meteorological conditions, using satellite data and meteorological analyses to provide context for ACE measurements and the Eureka campaigns. Data from long-lived trace gases measured by MLS and ACE-FTS allow exploration of the implications of the extreme meteorological conditions for transport. The results shown here are used to provide a meteorological context for measurement interpretation and validation presented in other papers in this Special Issue on ACE Validation.

\section{Data descriptions}

\subsection{Eureka lidar temperature data}

Environment Canada operated a stratospheric ozone and temperature lidar, AStrO DIfferential Absorption Lidar (AStrODIAL) at PEARL, during the winters of 2004 TO 2006.

The AStrO DIfferential Absorption Lidar (AStrO-DIAL) at PEARL has made measurements since 1993 focusing on the polar sunrise period; it was operated by Environment Canada during the Eureka campaigns in 2004 through 2006. Carswell et al. (1996) give a detailed description of the instrument, which uses a $\mathrm{XeCl}$ Excimer laser (Lumonics 600) with $50 \mathrm{~W}$ output power at $308 \mathrm{~nm}(300 \mathrm{~Hz})$, and a hydrogen Raman cell to convert some of the energy to $353 \mathrm{~nm}$. The data acquisition system provides five minute averaged profiles with different chopper and filter combinations (to minimize non-linearity effects in the photomultiplier tubes and screen out optically thick cloud events); these profiles are pasted together and averaged to provide nightly profiles with $300 \mathrm{~m}$ vertical resolution. Rayleigh temperature profiles are calculated at $353 \mathrm{~nm}$ (which is much less sensitive to ozone absorption than the $308 \mathrm{~nm}$ channel) using the ideal gas law and assuming hydrostatic equilibrium as described by Hauchecorne and Chanin (1980). Initially, a constant initial temperature seed at $70 \mathrm{~km}$ of $220 \mathrm{~K}$ was used; this is consistent with lower lidar than ACE temperatures near the

Schwartz, M. J., Daffer, W. H., Livesey, N. J., Mlynczak, M. G., Remsberg, E. E., Russell III, J. M., and Waters, J. W.: The evolution of the stratopause during the 2006 major warming: Satellite Data and Assimilated Meteorological Analyses, J. Geophys. Res., submitted, 2007. Available at http://mls.jpl.nasa.gov, 2007b. 
top of average lidar profile comparisons for Eureka in 2004 and 2006 (when 70-km temperatures were much higher than $220 \mathrm{~K}$, Sect. 4.1) and slightly higher lidar than ACE values in 2005 (when 70-km temperatures were often lower than $220 \mathrm{~K}$ ) shown in Sica et al. (2007). Large temperature variability at Eureka makes selection of the seed problematic; to reduce biases in the top $10-15 \mathrm{~km}$ of the profiles, the SABER (Sect. 2.4) temperatures interpolated to Eureka's location and $70 \mathrm{~km}$ were used for the seed in the profiles shown here. A final calibration factor is applied based on temperature data from the top three kilometres of Eureka radiosonde profiles. Lidar temperature profiles typically extend below $30 \mathrm{~km}$, depending on aerosol/cloud conditions.

The statistical error in the temperature profiles shown here above $\sim 50 \mathrm{~km}$ altitude can be significant $(\sim 20 \mathrm{~K})$ due to the limited statistics from the low signal strength. However, as shown by Duck and Greene (2004, and references therein), even at the highest altitudes, lidar temperature profiles can capture gravity waves and other small vertical scale structure that is absent in lower resolution profiles from satellites.

\subsection{ACE-FTS data}

SCISAT-1, the satellite carrying the ACE mission (Bernath et al., 2005) was launched in August 2003. The primary instrument is the ACE-FTS, a Fourier transform spectrometer featuring high resolution $\left(0.02 \mathrm{~cm}^{-1}\right.$, corresponding to a $\pm 25 \mathrm{~cm}$ maximum optical path difference) and broad spectral coverage in the infrared $\left(750-4400 \mathrm{~cm}^{-1}\right)$. ACE-FTS works primarily in the solar occultation mode, collecting atmospheric limb measurements using the sun as a radiation source. Latitudes of ACE-FTS measurements vary over an annual cycle with coverage as high as $\pm 85^{\circ}$ and an emphasis on the polar regions in winter and spring; vertical resolution is $\sim 3-4 \mathrm{~km}$. Version 2.2 (including updates for $\mathrm{O}_{3}, \mathrm{H}_{\mathrm{D}} \mathrm{O}$ and $\mathrm{N}_{2} \mathrm{O}_{5}$ ) of the ACE-FTS retrievals (Boone et al., 2005) is used here. ACE-FTS temperatures are retrieved only above $12 \mathrm{~km}$; below that they are constrained to values from Canadian Meteorological Center (CMC) analyses. Temperature precision is typically $\sim 2-4 \mathrm{~K}$ through the stratosphere, and $\sim 4-7 \mathrm{~K}$ in the mesosphere. Initial validation studies using ACE-FTS version 1.0 (McHugh et al., 2005; Kerzenmacher et al., 2005) and version 2.1 (Froidevaux et al., 2006) temperatures showed agreement to within $\sim 2.5 \mathrm{~K}$ or better with correlative measurements from $10-45 \mathrm{~km}$. ACE-FTS v2.2 temperatures are validated by Sica et al. (2007, this issue). Initial validation of v1.0 ACE-FTS temperature and trace gases was presented in a 2005 special section of Geophysical Research Letters (e.g., Walker et al., 2005; McHugh et al., 2005; Petelina et al., 2005; Fussen et al., 2005; Mahieu et al., 2005; Jin et al., 2005; Clerbaux et al., 2005). Detailed validation studies of the baseline ACE-FTS v2.2 trace gases, including $\mathrm{CO}$ (Clerbaux et al., 2007) and $\mathrm{N}_{2} \mathrm{O}$ (Strong et al., 2007) are presented in papers in this special issue of Atmospheric Chemistry and Physics.

\subsection{Aura MLS data}

NASA's Aura satellite, launched in July 2004, carries the Earth Observing System Microwave Limb Sounder (MLS) instrument, which has been taking daily global data since mid-August 2004. MLS measures millimeter- and submillimeter-wavelength thermal emission from the limb of Earth's atmosphere. Detailed information on the measurement technique and the Aura MLS instrument is given by Waters et al. (2006). The Aura MLS fields-of-view point in the direction of orbital motion and vertically scan the limb in the orbit plane, leading to data coverage from $82^{\circ} \mathrm{S}$ to $82^{\circ} \mathrm{N}$ latitude on every orbit. Vertical profiles are measured every $165 \mathrm{~km}$ along the suborbital track.

MLS data are currently being reprocessed with version 2.2 (v2.2) algorithms; reprocessing will be complete within a year. Most of data during the 2004-2005 and 2005-2006 Arctic winters have been reprocessed and are used here. Schwartz et al. (2007) validated MLS v2.2 temperatures. Vertical resolution for MLS v2.2 temperature is $\sim 5 \mathrm{~km}$ in the upper troposphere and near the tropopause, $\sim 4 \mathrm{~km}$ in the stratosphere, and $\sim 8-9 \mathrm{~km}$ near the stratopause and in the lower mesosphere; precision is better than $\sim 1 \mathrm{~K}$ through the upper stratosphere, degrading to $2-2.5 \mathrm{~K}$ above that (Schwartz et al., 2007). Detailed validation of v2.2 MLS trace gases shown here is given by Lambert et al. (2007) for $\mathrm{N}_{2} \mathrm{O}$ and $\mathrm{H}_{2} \mathrm{O}$ Pumphrey et al. (2007) for CO.

Quality control recommendations given in Livesey et al. (2007) and in the Aura Validation Issue papers cited above are used to screen the MLS data.

\subsection{SABER data}

The Sounding of the Atmosphere using Broadband Emission Radiometry (SABER) (Mlynczak and Russell, 1995) instrument, launched on the Thermosphere Ionosphere Mesosphere Energetics and Dynamics satellite in December 2001, measures profiles of kinetic temperature using $15-\mu \mathrm{m}$ and 4.3- $\mu \mathrm{m} \mathrm{CO} 2$ limb-emission radiance measurements. Pressure is measured from spectral contrast and temperature is then inferred from pressure and pointing heights assuming hydrostatic equilibrium. The effective vertical resolution of SABER temperature is $\sim 2 \mathrm{~km}$ although it is retrieved on a higher-resolution fixed set of pressure surfaces (Remsberg et al., 2003). Version 1.06 (v1.06) SABER temperatures are used here. Precision of the SABER temperatures is of order $1 \mathrm{~K}$ or better in the stratosphere, but becomes somewhat larger $(\sim 1.5 \mathrm{~K})$ by the middle mesosphere. Test days of the Version 1.06 (v1.06) SABER temperatures compare very well with correlative profiles and with profiles from the Upper Atmosphere Research Satellite (UARS) HALOE (see also Remsberg et al., 2002). Non-local-thermodynamic equilibrium effects in the very cold conditions $(\sim 130 \mathrm{~K})$ of the summer polar mesopause (near $85 \mathrm{~km}$ ) are not modeled well in SABER v1.06, leading to a mesopause that is $\sim 3 \mathrm{~km}$ 
too low compared to climatological and falling spheres data (Kutepov et al., 2006); that discrepancy has been corrected in v1.07. The v1.06 bias in that region is not a factor for the wintertime conditions shown here.

\subsection{Meteorological datasets}

The Goddard Earth Observing System Version 4.03 (GEOS-4) analyses are the primary gridded meteorological dataset used here. We show a comparison of upper stratospheric/lower mesospheric temperatures with GEOS5 (GEOS Version 5.0.1) and European Centre for MediumRange Weather Forecasts (ECMWF) analyses, the other operational systems that now provide analyses extending through the lower mesosphere (to $0.01 \mathrm{hPa}$ ); neither of the latter two datasets is currently available for all of the three years discussed here. Manney et al. (2007b) ${ }^{3}$ show temperature comparisons between GEOS-5, ECMWF, and the MLS and SABER satellite measurements during the 2005-2006 Arctic winter. The analyses shown here are briefly described below.

The GEOS-4 analyses are described by Bloom et al. (2005); the assimilation procedure uses a Physical Space Statistical Analysis Scheme. GEOS-4 data are provided on 55 hybrid $(\sigma /$ pressure) model levels from the surface to $0.01 \mathrm{hPa}$. The horizontal grid is $1.0^{\circ}$ latitude by $1.25^{\circ}$ longitude; six-hourly average fields are provided centered at 00:00, 06:00, 12:00 and 18:00 UT. Besides the standard meteorological variables, GEOS-4 products include potential vorticity (PV) calculated internally in the model. GEOS5 analyses (Reinecker et al., 2007) have been produced for the period of the Aura mission, from August 2004 through the present, and have now replaced GEOS-4 as the ongoing operational system. GEOS-5 uses the Gridpoint Statistical Analysis method of Wu et al. (2002), a 3-D-Var system, and a six-hour analysis window. GEOS-5 analyses are provided on 72 model levels from the surface to $0.01 \mathrm{hPa}$, and a $0.5^{\circ}$ latitude by $2 / 3^{\circ}$ longitude grid. Both GEOS-4 and GEOS-5 use a simple non-orographic gravity-wave parameterization (Garcia and Boville, 1994) to represent waves with non-zero phase speed that are important in the upper stratosphere and mesosphere.

ECMWF analyses are from a 4-D-Var system based on a spectral general circulation model (e.g., Simmons et al., 2005). ECMWF data shown here are from the T799/91level system with a top at $0.01 \mathrm{hPa}$ that became operational in February 2006 (e.g., Untch et al., 2006, and other ECMWF newsletters, available at http://www.ecmwf.int/publications/ newsletters/), for which we have obtained pre-operational data for several months prior to that. Data from the T799/91level system were provided on model levels up to $0.01 \mathrm{hPa}$, on a $2.5^{\circ} \times 2.5^{\circ}$ horizontal grid. ECMWF uses Rayleigh friction at altitudes above $5 \mathrm{hPa}$ to slow down the otherwise too strong polar night jet. ECMWF analyses prior to the 2005-
2006 winter were from a system with a lower top, and are not available above $0.1 \mathrm{hPa}$.

\subsection{Data handling for Eureka and ACE-FTS comparisons}

For examination of data at specific locations, either at Eureka or those coincident with ACE-FTS measurements, gridded meteorological analyses and products derived from them are interpolated bi-linearly to the locations in question. For ACE-FTS, and some Eureka comparisons, pre-calculated "Derived Meteorological Products" (DMPs) are available from GEOS-4, and/or GEOS-5 analyses (Manney et al., 2007a).

For Eureka comparisons and overviews, all ACE, MLS and SABER profiles taken on the same day within $2^{\circ}$ latitude and $8^{\circ}$ longitude of Eureka are used. For ACE-FTS and SABER, this is no more than one profile per day; for MLS, it is typically four to eight profiles per day, which are averaged (with each given equal weight) to get the daily profiles shown. The same geographic criteria are used to determine whether a SABER or MLS profile is coincident with ACE-FTS, but data are constrained to within $12 \mathrm{~h}$ before or after each ACE-FTS measurement; again, MLS profiles coincident with an ACE-FTS occultation are averaged to get a single profile for each day.

"Vortex-averages" of ACE-FTS and MLS data colocated with ACE are calculated as described by Manney et al. (2007a): The GEOS-4 ACE DMPs and GEOS-5 MLS DMPs provide the "scaled" PV (sPV; in "vorticity units" Dunkerton and Delisi, 1986; Manney et al., 1994) that is used to define the vortex boundary for these calculations. MLS data taken within $\pm 1^{\circ}$ latitude, $\pm 8^{\circ}$ longitude, and $12 \mathrm{~h}$ of all ACE profiles inside the vortex are included in the averages.

\section{Synoptic overview of the 2004, 2005 and 2006 late winters}

Figures 1 through 3 show maps of sPV in the upper, middle and lower stratosphere. The same three days, chosen during the Eureka campaigns and to coincide with specific comparisons shown below, are described in each year, to contrast the meteorological conditions. Locations of Eureka and of ACE-FTS measurements are indicated.

After the major warmings in January 2004 and 2006, the upper stratospheric vortex (Fig. 1) redeveloped to be unusually large and strong by 24 February (Fig. 1); in contrast, in 2005, the upper stratospheric vortex had weakened by this time (as is more common for late February) and was distorted and shifted off of the pole by strong wave activity leading to the final warming. By 6 March, the 2004 and 2006 upper stratospheric vortices were still very strong, while the 2005 vortex was breaking down at the start of the major final warming and moved away from Eureka as it decayed. By 18 March 2005, the vortex breakup had progressed so 


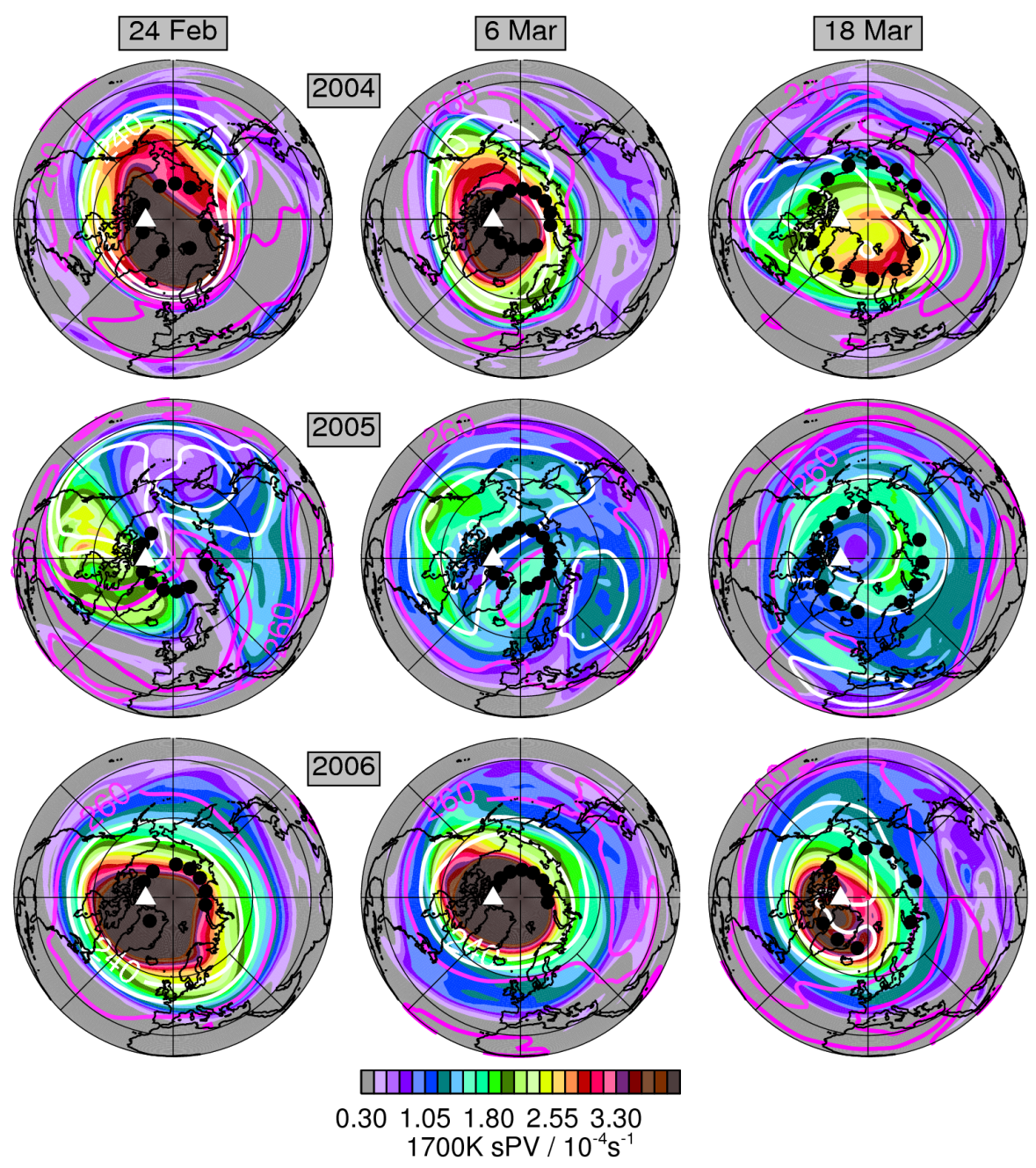

Fig. 1. Maps of scaled potential vorticity (sPV, $\left.10^{-4} \mathrm{~s}^{-1}\right)$ from GEOS-4 on the $1700 \mathrm{~K}$ isentropic surface $(\sim 1.5 \mathrm{hPa}, \sim 50 \mathrm{~km})$ on $($ left to right) 24 February, 6 March and 18 March in (top to bottom) 2004 through 2006. Contours are GEOS-4 temperatures of 240, 250,260 and $270 \mathrm{~K}$ (lower two white, higher two red). Black dots show ACE-FTS observation locations and white triangles show the location of Eureka. Projection is orthographic, from $0^{\circ}$ to $90^{\circ} \mathrm{N}$, with $0^{\circ}$ longitude at the bottom and $90^{\circ} \mathrm{E}$ to the right.

that there was an anticyclone (low sPV) over the pole with an elongated vortex remnant surrounding it. The 2004 and 2006 vortices were still strong and positioned over Eureka on 18 March, but had started to weaken and shrink. Most ACE measurements were inside the vortex in the middle and upper stratosphere in 2004 and 2006, while in 2005 many were outside or in vortex remnants. The upper stratosphere thus presents an apparently contrary picture in the high Arctic in February and March, wherein the so-called warm, disturbed years had colder, stronger vortices in the upper stratosphere in late winter and spring than the "unusually cold" year.

In the middle stratosphere (Fig. 2), the 2004 and 2006 vortices were still recovering and strengthening slowly after the prolonged SSWs during 24 February through 18 March; the vortex redeveloped more strongly in 2004 than in 2006, such that during the early part of the 2006 Eureka campaign, the middle stratospheric vortex was still very weak; in both years, the vortex was over Eureka in March, with lowest temperatures over the pole, and the vortex edge over Eureka in late February. During the 2005 campaign, the vortex was weakening and shifted off the pole as the major final warming started - that SSW qualified as major (that is, easterly winds north of $60^{\circ} \mathrm{N}$ down to $10 \mathrm{hPa}$ ) on 10 March 2005. By 18 March 2005, the final warming had progressed so that a large, elongated vortex remnant was located well off the pole equatorward of $60^{\circ} \mathrm{N}$, and high temperatures were over the pole (and Eureka). ACE measurements covered both vortex and extravortex conditions in all three years, but were primarily inside the vortex in early March 2004 and 2006. Thus, like the upper stratosphere, the Arctic during the period of the Eureka campaigns in the disturbed 2004 and 2006 winters had a stronger, colder, more pole-centered vortex than the overall much colder 2005 winter. 
In the lower stratosphere (Fig. 3), because radiative cooling is much slower and the effects of the SSW propagate down later, the 2004 and 2006 vortices never recovered substantially more after the SSWs. The 2006 vortex in late winter was even smaller and weaker than that in 2004. In 2005, the lower stratospheric vortex was strong, but distorted and variable throughout the winter (e.g. Manney et al., 2006b), as seen here on 24 February and 6 March. By 18 March 2005, with the major final warming in progress, the vortex was becoming even more active; a few days after this, it broke into two fragments and continued to decay. The vortex edge was over Eureka in 2005 until $~ 8$ March 2005. ACE measurements sampled both vortex and extravortex conditions in all three years.

\section{The 2004, 2005 and 2006 late winters at Eureka}

\subsection{Overview from MLS, SABER, and meteorological analyses}

An overview of the temperature evolution in relation to the vortex at Eureka is shown in Fig. 4, using temperatures from MLS and SABER measurements coincident with Eureka and from GEOS-4 analyses interpolated to Eureka's location. The sPV contours on the GEOS-4 panels demark the position of the vortex edge in the stratosphere $(\sim 200-0.7 \mathrm{hPa})$. In the early winter, Eureka was well inside the vortex in each year (black contour farther into the vortex was last to pass over Eureka). In the cold 2004-2005 winter, with no strong midwinter SSWs, the vortex remained over Eureka until late February to early March (depending on the altitude) when it began its early springtime breakup. The decreasing SPV values (black, then white contour over Eureka) show the vortex edge crossing Eureka's location as it moved away from the pole during its final breakup. In 2003-2004, the prolonged major SSW began in late December, at which time the vortex moved away from Eureka. Similar behavior was seen in 2005-2006, but beginning in early to mid-January. In these years, a pole-centered upper stratospheric vortex redeveloped strongly and quickly after the SSW (cf. Fig. 1), remaining over Eureka for the duration of the 2004 and 2006 validation campaigns. That the SPV contours suggest extravortex air over Eureka in the lower stratosphere during the campaigns does not necessarily indicate a vortex located away from $\mathrm{Eu}-$ reka, but reflects how weak and ill-defined the vortex was during these periods. Thus, because of the different extremes in the meteorological conditions, the Eureka campaigns in 2004 and 2006 were conducted within the Arctic vortex at altitudes where it had redeveloped, while that in 2005 was conducted primarily outside or at the edge of the vortex.

The sPV scaling used becomes inappropriate near the stratopause, since the static stability there becomes very different from the value assumed in the PV scaling; the contours shown typically lie just below the stratopause as defined by the temperature maximum, and thus provide another indication of the stratopause altitude. In early winter in each year, the stratopause at Eureka lies near 55-60 km, consistent with previous studies (e.g., Hitchman et al., 1989) that show it to be at higher altitude and separated from the midlatitude stratopause as a result of gravity wave driven processes. In 2004-2005, the stratopause altitude remains near that level throughout the winter, dropping slightly in spring, and its position as represented in MLS, SABER and GEOS4 agrees well. As reported by Manney et al. $(2007)^{3}$, during the 2006 major SSW, the stratopause dropped to near $30 \mathrm{~km}$ and then became ill-defined in late January; similar behavior has been seen during previous strong SSWs (e.g., Labitzke, 1972). In early February, it reformed at very high altitude, near $80 \mathrm{~km}$ over Eureka, and began dropping and warming rapidly during the strong vortex recovery in the upper stratosphere/lower mesosphere. Siskind et al. (2007) showed model simulations indicating that the very high stratopause in early February 2006 resulted from filtering by the disturbed stratospheric flow at lower altitudes of gravity waves that would normally break near $50 \mathrm{~km}$, and that are critical in determining the climatological polar stratopause structure (Hitchman et al., 1989; Siskind et al., 2007, and references therein). The 2006 Eureka campaign began just after the reformation of the stratopause at very high altitude. As discussed by Manney et al. (2007) ${ }^{3}$, GEOS-4 and other operational analyses (including GEOS-5 and ECMWF, see below), which are not constrained by data above $\sim 50 \mathrm{~km}$, use models with tops no higher than $0.01 \mathrm{hPa}$ (near $80 \mathrm{~km}$ ), and include very simplified parameterizations of non-orographic gravitywave drag, underestimate the variations in stratopause altitude, and show it reforming much too low. The SABER data in 2004 don't cover the Arctic during the SSW or at the beginning of the recovery, but the GEOS-4 data and the subsequent SABER evolution suggest that very similar behavior occurred during the 2003-2004 winter.

The evolution of the coldpoint, the temperature minimum in the stratosphere, is quite distinct from that of the tropopause (the latter is the shallow local minimum near $250-400 \mathrm{hPa}$ seen in GEOS-4). During most of the cold 2004-2005 winter, and before the SSWs in 2004-2005 and 2005-2006, the deepest temperature minimum is between 100 and $30 \mathrm{hPa}$. After the SSWs started in 2004 and 2006, that temperature minimum became very shallow and dropped in altitude. As the stratopause reformed at very high altitude, a strong temperature minimum formed below it near $3 \mathrm{hPa}$ ( $\sim 45 \mathrm{~km}$ ) and gradually moved down. Thus the coldpoint was near 10-3 hPa during the 2004 and 2006 Eureka campaigns, but near $30-60 \mathrm{hPa}$ in 2005 . We detail stratopause and tropopause evolution more quantitatively below.

Figure 5 show the time evolution of the stratopause at Eureka from MLS, SABER and GEOS-4; GEOS-5 and ECMWF values are also shown for periods when they are available (ECMWF values are shown after values are available up to $0.01 \mathrm{hPa}$ ). While the analyses cannot 


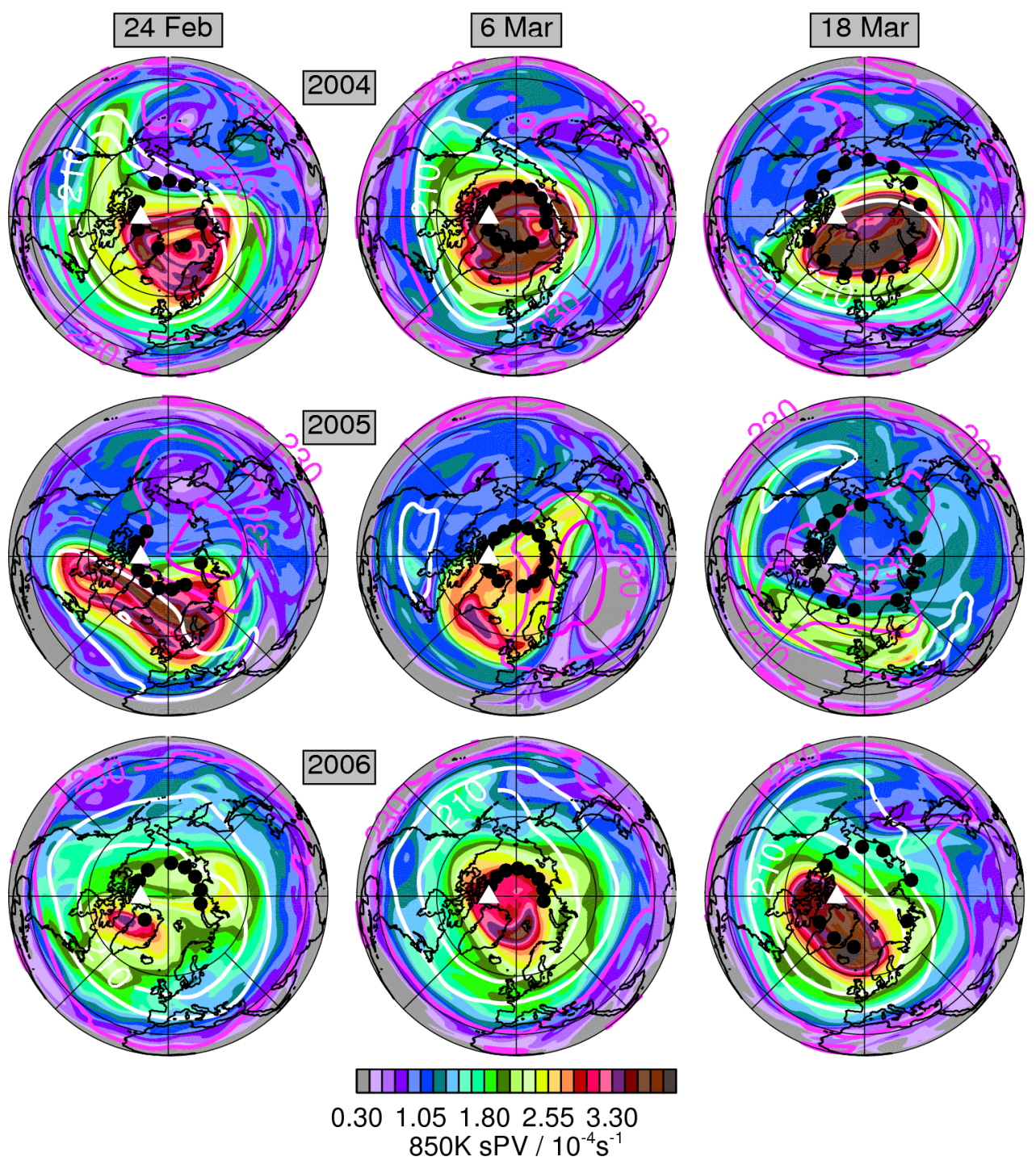

Fig. 2. As in Fig. 1, but at $850 \mathrm{~K}(\sim 10 \mathrm{hPa}, \sim 30 \mathrm{~km})$, and with temperature overlays of $210,220,230$ and $240 \mathrm{~K}$ (lower two white, higher two red).

accurately capture the stratopause behavior during the aftermath of the 2004 and 2006 SSWs, they do capture the behavior in 2006 fairly accurately as the stratopause drops and cools during the SSW, suggesting that GEOS-4 gives a reasonable representation of the similar period period in 2004, when MLS had not yet been launched and SABER was viewing high southern-hemisphere latitudes. Before and during the major SSWs, and throughout the 2004-2005 winter, the GEOS-4 stratopause is slightly warm compared to the satellite data; as discussed in more detail by Manney et al. $2007^{3}$, this failing is alleviated to some degree in GEOS-5, and ECMWF early winter stratopause temperatures agree well with MLS and SABER. After the 2004 and 2006 SSWs, differences between the analyses and the satellite data increase dramatically: The GEOS-4 stratopause becomes much too warm, even after the stratopause has dropped to typical altitude and its position is once again accurately captured by GEOS-4; in contrast, the ECMWF stratopause becomes much too cool until mid-March, and the GEOS-5 stratopause too cool when the stratopause is highest, but too warm after late February 2006. As discussed by Manney et al. $2007^{3}$, both the low model tops (near $0.01 \mathrm{hPa}$, very close the highest level of the stratopause) and the simplified gravity-wave drag parameterizations are thought to play important roles in the failure of the analyses to capture the stratopause evolution under extreme conditions. MLS and SABER stratopause altitudes and evolution typically agree very well; when the stratopause altitude is very high after the 2006 SSW, MLS temperatures are lower than SABER, but agree quite well when it is near $50-60 \mathrm{~km}$ in 2005 , before the stratopause 


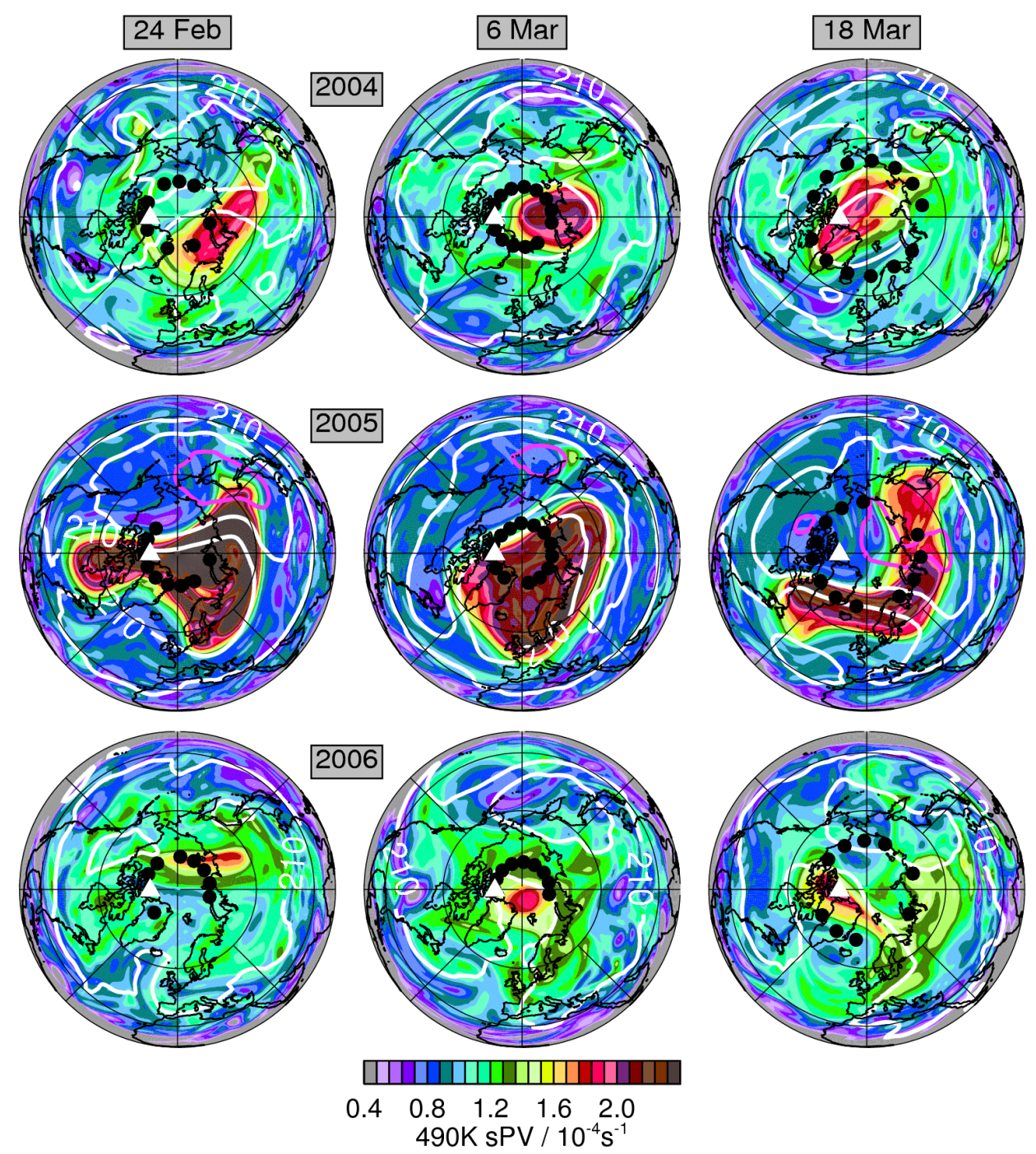

Fig. 3. As in Fig. 1, but at $490 \mathrm{~K}(\sim 50 \mathrm{hPa}, \sim 18 \mathrm{~km})$, and with temperature overlays of $215,220,225$ and $230 \mathrm{~K}$ (lower two white, higher two red).

breakdown after the SSW in 2006, and after it has dropped in late February through March 2006. Schwartz et al. (2007) reported an MLS global-mean low bias of up to $8 \mathrm{~K}$ between $\sim 0.3$ and $0.01 \mathrm{hPa}$ (largest between 0.3 and $0.1 \mathrm{hPa}$ ), and near-zero bias near $1 \mathrm{hPa}$, with respect to several correlative datasets; the coarsening MLS vertical resolution may also tend to result in an underestimate of stratopause temperature at higher altitudes.

The evolution of the tropopause at Eureka is shown in Fig. 6 using GEOS-4 analyses. Because the analyses are quite well-constrained by data below $\sim 10 \mathrm{hPa}$, and the atmospheric processes parameterized in the models are better understood than those near and above the stratopause, GEOS-4 should provide an accurate picture of this region; GEOS-4, GEOS-5, ECMWF, and other analyses (such as those from the Met Office) all indicate very similar behavior in each year, and agree closely with radiosonde observations at Eureka (not shown). SABER measurements do not, and MLS often do not, extend low enough to capture the polar winter tropopause. We show the tropopause calculated from the WMO (temperature gradient) definition, using the algorithm of Reichler et al. (2003), and a "dynamical" definition using the 3.5 PVU PV contour (which Highwood and Berrisford (2000) and Schoeberl (2004) have shown to be appropriate for the extratropics); the coldpoint is also shown. The search for a tropopause is halted if it is not found at a pressure higher than $10 \mathrm{hPa}$ (altitude less than $\sim 30 \mathrm{~km}$ ); the search for the coldpoint extends to $1 \mathrm{hPa}$. The WMO and dynamical tropopause altitudes and temperatures agree quite well throughout, and the PV at the WMO tropopause typically ranges from $\sim 2$ to $\sim 5 \mathrm{PVU}$, fairly symmetrically around the dynamical value; the tropopause thus defined coincides 

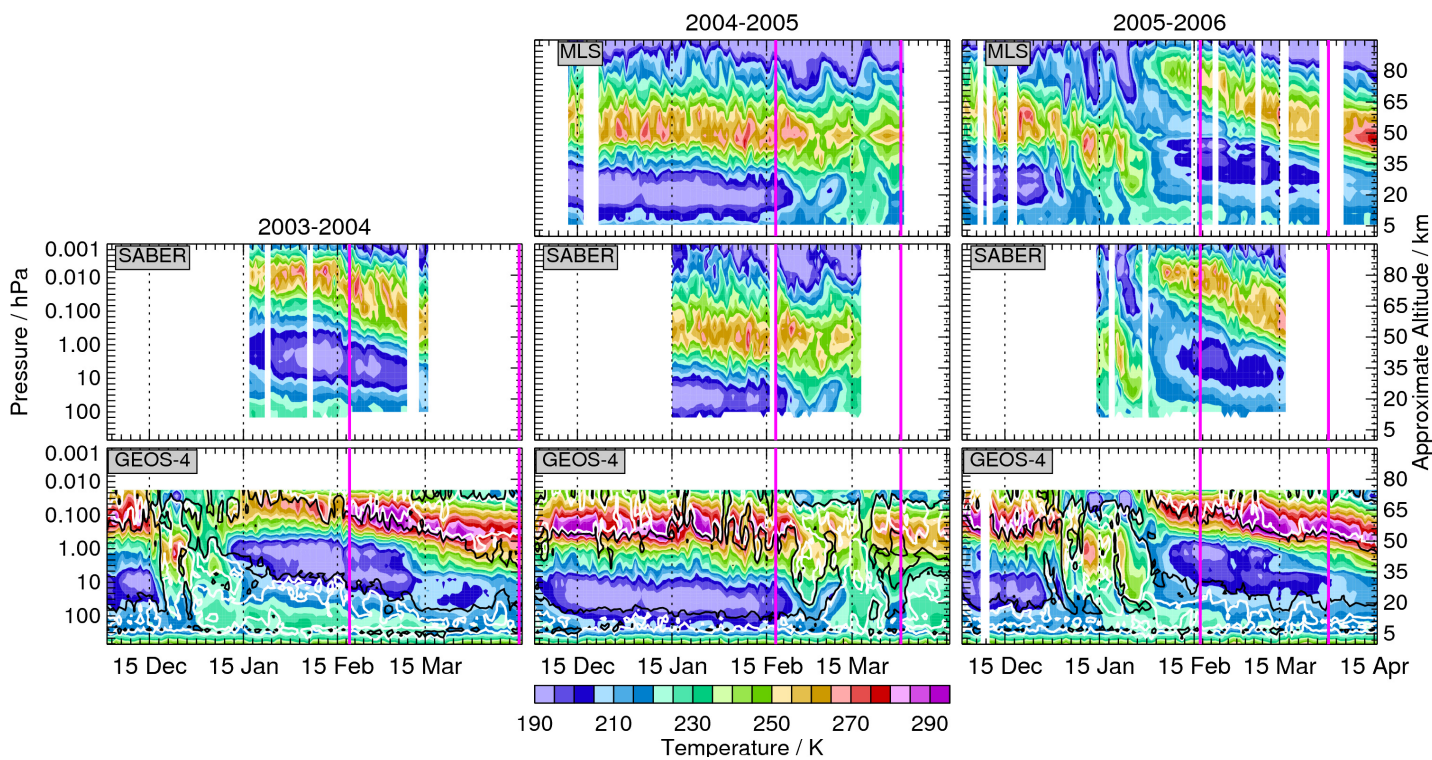

Fig. 4. Cross-sections of temperature (K) at Eureka as a function of time from December through April in (left to right) $2003-2004$ through 2005-2006 from (top to bottom) MLS, SABER and GEOS-4. MLS and SABER are averages of all profiles within $2^{\circ}$ latitude and $8^{\circ}$ longitude of Eureka on each day; GEOS-4 values are bilinearly interpolated to Eureka's location. Overlays on GEOS-4 plots are 1.2 and $1.6 \times 10^{-4} \mathrm{~s}^{-1} \mathrm{sPV}$ contours; these values are typically in the vortex edge region in the stratosphere (see text), so going from white to black in time shows the vortex moving over Eureka, and black to white shows it moving away from Eureka. Magenta lines show periods of Eureka campaigns each year.
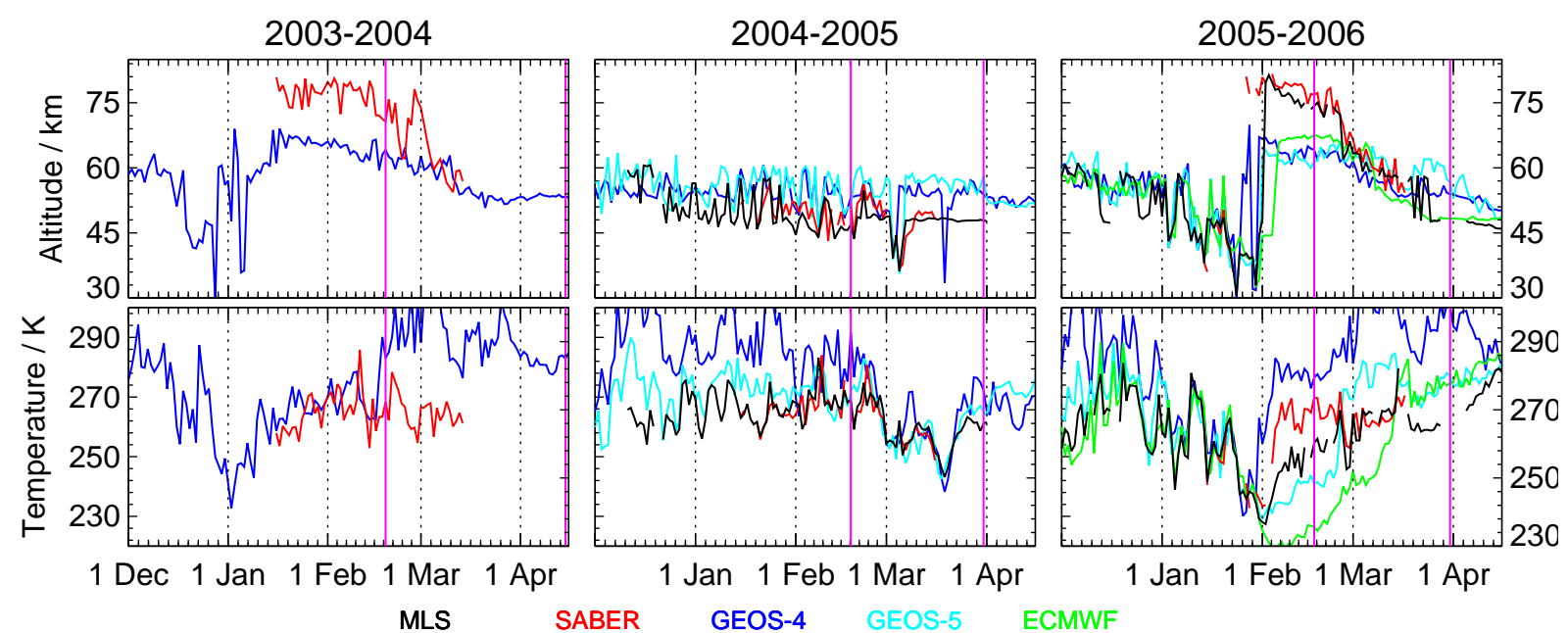

Fig. 5. Timeseries in (left to right) 2003-2004, 2004-2005 and 2005-2006 of MLS, SABER and GEOS-4 stratopause (top) altitude (km) and (bottom) temperature (K) at Eureka. MLS values are in black, SABER in red, GEOS-4 in blue. Values from GEOS-5 (cyan) are included on the 2004-2005 and 2005-2006 panels, and from ECMWF (green) on the 2005-2006 panels. Magenta lines show periods of Eureka campaigns.

with the shallow temperature minimum near $250-400 \mathrm{hPa}$ $(5-8 \mathrm{~km})$ mentioned above. In contrast (note radically different altitude scales), the coldpoint value varies from $\sim 8$ to over $40 \mathrm{~km}$ in 2004 and 2006. During 2004 and 2006, the temperature minimum is near $3 \mathrm{hPa}$ at the beginning of the recovery from the SSWs, during the first part of the Eureka campaigns, dropping to near $10 \mathrm{hPa}(\sim 30 \mathrm{~km})$ in March.
During most of the 2005 winter, the coldpoint was near 20$25 \mathrm{~km}$ and up to $\sim 25 \mathrm{~K}$ colder than the tropopause. After the final warming in 2005, the coldpoint coincided with the $\mathrm{WMO}$ and dynamical tropopauses. As shown in more detail below (Sect. 4.2), the variations in temperature extrema in the winters with prolonged SSWs are reflected in very unusual temperature profiles throughout the stratosphere. 

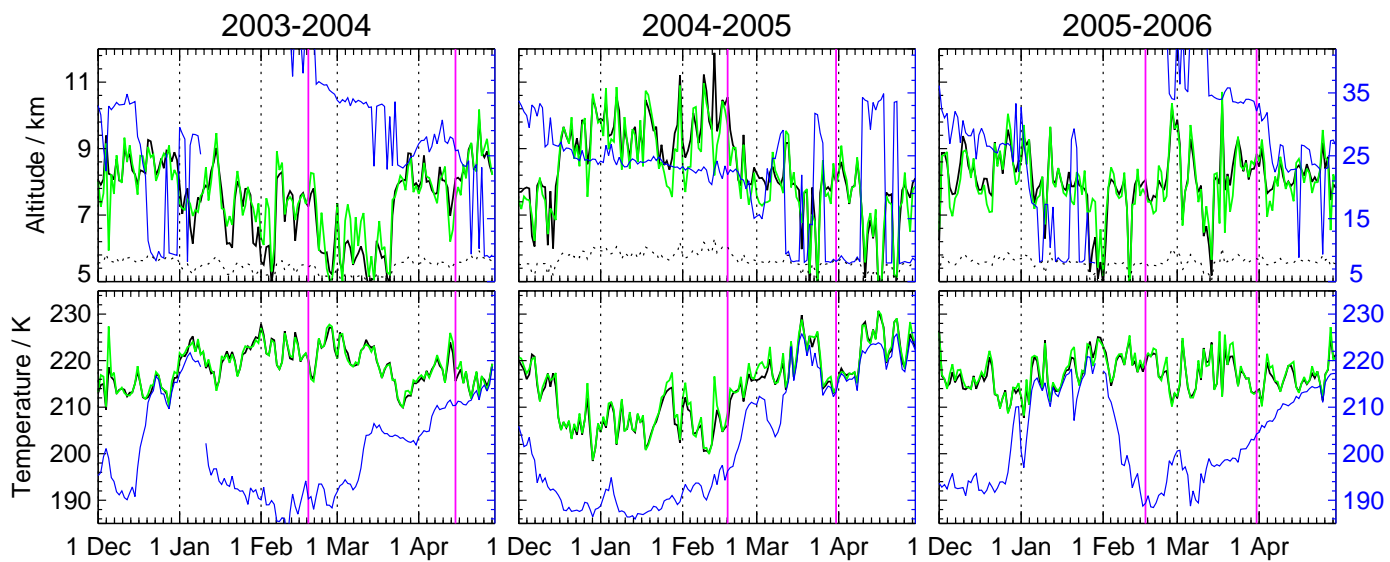

Fig. 6. Timeseries in (left to right) 2003-2004, 2004-2005 and 2005-2006 of GEOS-4 tropopause (top) altitude (km) and (bottom) temperature $(\mathrm{K})$ at Eureka. Tropopause from WMO (temperature gradient) definition is in black, from dynamical definition (3.5 PVU) in green, and "coldpoint" value in blue. The left-hand y-axis scale is for WMO and dynamical definitions, right-hand scale for cold point (ranges are the same only for temperature); dotted lines show the WMO tropopause altitude on the coldpoint scale. Magenta lines show periods of Eureka campaigns.

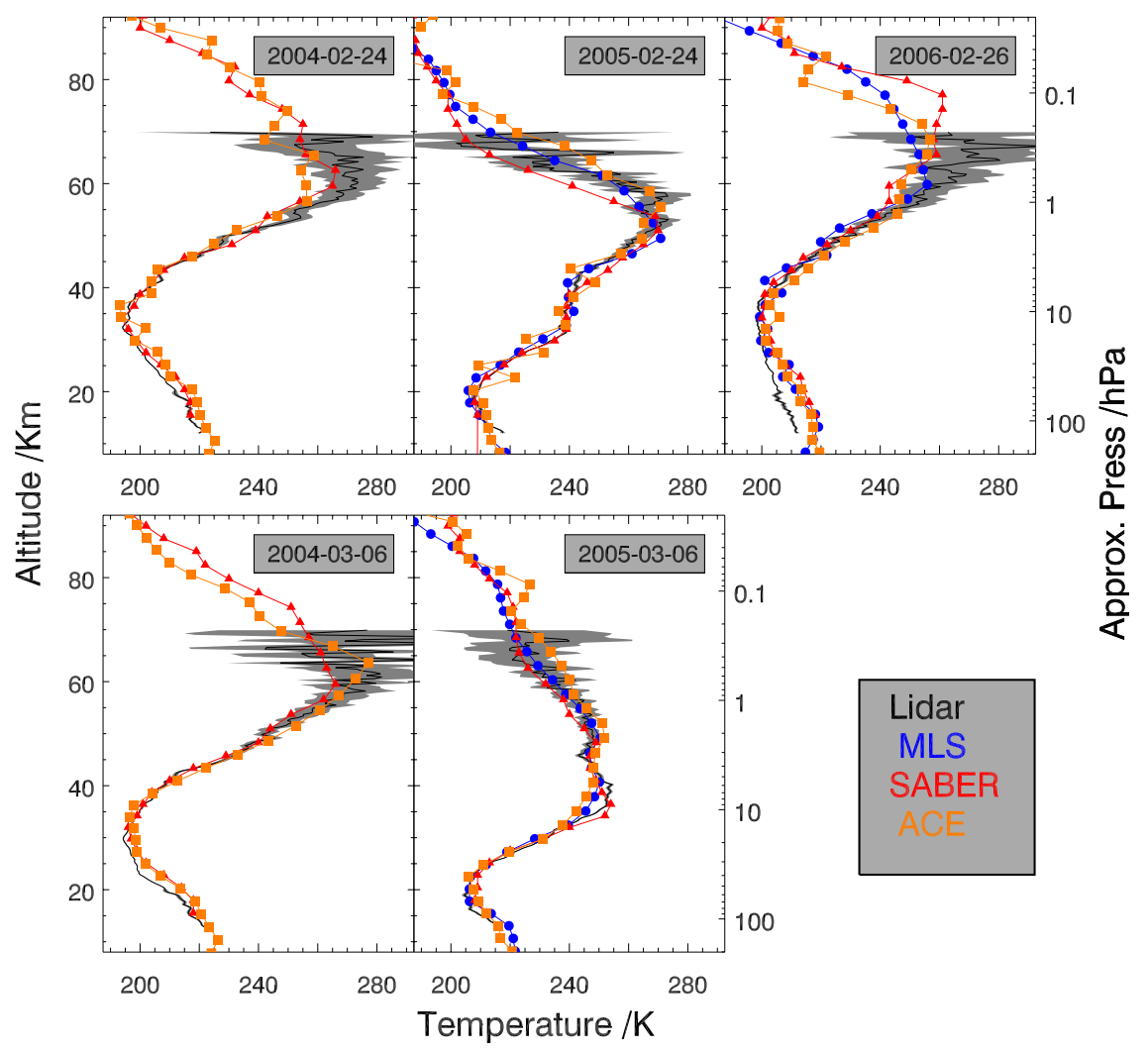

Fig. 7. Lidar profiles taken at Eureka on selected days in February and March 2004 and 2005, and February 2006, compared with coincident profiles from SABER (red lines with triangles), ACE-FTS (orange lines with squares), and MLS (blue lines with dots).

While tropopause variations during the SSWs are not as dramatic as those of the stratopause, the tropopause at Eureka was distinctly higher and colder in the 2004-2005 win- ter than the other two winters. Day-to-day variations dominate the variability, but it appears that the tropopause at the very high latitude of Eureka drops and warms during 


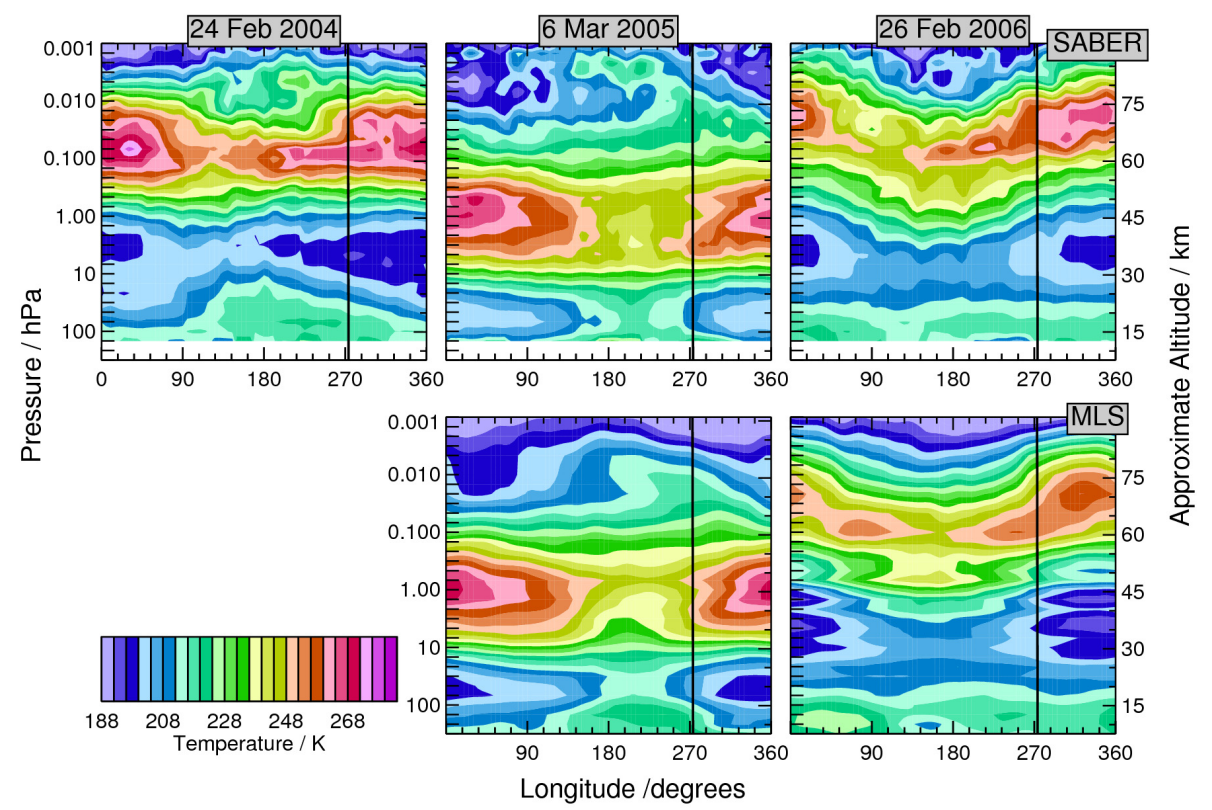

Fig. 8. Cross-sections of temperature from (top) SABER and (bottom) MLS around the $80^{\circ} \mathrm{N}$ latitude circle on (left) 24 February 2004 , 6 March 2005 and 26 February 2006. Vertical black line is at longitude of Eureka.

the SSWs, at the same time the stratopause is dropping and cooling. Examination of hemispheric tropopause structure (not shown) indicates a higher, colder tropopause prior to the SSWs at lower latitudes, near $\sim 60^{\circ} \mathrm{N}$, consistent with forcing of the warming related to upper tropospheric wave activity. The parallel evolution of the stratopause and tropopause clearly demonstrates coupling of the entire tropospherestratosphere-mesosphere system.

We show below profile comparisons of temperatures from ACE-FTS, MLS, and SABER satellite data with Eureka lidar data during the Eureka campaigns. These provide a close-up view of the striking differences in meteorological conditions in the high Arctic between the warmest and the coldest Arctic winters, and how those differences and local variations in meteorology can affect interpretation of the Eureka data.

\subsection{Comparisons with Eureka lidar}

Figure 7 shows selected lidar temperature profiles recorded at Eureka during the three winters, compared with MLS (2005 and 2006), SABER, and ACE-FTS.

Comparing the profiles in late February of 2004, 2005 and 2006 (Fig. 7, top row) shows the striking difference in temperature structure at Eureka for the two types of extreme conditions represented in these winters: In 2005, the profiles show a broad temperature minimum between $\sim 300$ and $30 \mathrm{hPa}(\sim 10-25 \mathrm{~km})$, and a sharp temperature maximum near 1 to $0.3 \mathrm{hPa}(\sim 55-60 \mathrm{~km})$; this is a characteristic wintertime temperature structure in the Arctic. In contrast, in February 2004 and 2006, there was a shallow temperature minimum near $300-400 \mathrm{hPa}$ (below $10 \mathrm{~km}$, not seen here), followed by a gradual decrease in temperature up to 3 to $1 \mathrm{hPa}(\sim 35-45 \mathrm{~km})$, with a strong temperature maximum between 0.1 and $0.01 \mathrm{hPa}(\sim 65-80 \mathrm{~km})$. Thus, the conditions during the recovery from the prolonged SSWs led to temperatures that decreased with altitude through most of the stratosphere (commonly defined as the region where temperature increases with altitude). The profile in March 2004 shows the stratopause and coldpoint altitudes beginning to drop, but still much higher than the more typical profile for March 2005 (no Eureka lidar data were taken in March 2006).

There is quite good agreement between the lidar profiles and those from each of the satellite instruments below $\sim 55$ $60 \mathrm{~km}(0.1$ to $0.6 \mathrm{hPa})$, and usually higher, with the satellite data nearly always falling within the lidar uncertainty estimates. A more detailed look at the temperature structure in the region surrounding Eureka from MLS and SABER data shows that many features where lidar and satellite profiles appear to disagree may be explained by local temperature variations.

On 24 February 2004, lidar, ACE-FTS and SABER profiles all show a notch near the stratopause; this feature appears in some or all of the instruments' profiles on some, but not other, surrounding days. Figure 8 (left panels) shows a cross-section of SABER temperature at $80^{\circ} \mathrm{N}$ on 24 February 2004, with the longitude of Eureka indicated. There is a double-peak in stratopause temperature extending over Eureka; this is the root of the secondary temperature maximum that extends upward and equatorward from the primary stratopause during this period discussed by Manney et 
al. $2007^{3}$. Note also that Eureka is at the edge of a region with very strong gradients in stratopause temperature and altitude. This suggests that the temperature differences between instruments at this time are real atmospheric features with small horizontal extent such that they may be captured by some but not other instruments on any given day depending on the exact measurement location. The stratopause altitude as seen in SABER data is fairly constant in the region around Eureka on 24 February 2004; consistent with this, the stratopause altitude in the lidar profile appears to agree well with that in SABER and ACE-FTS.

On 6 March 2005, there is a laminar structure in the profiles, with a local temperature minimum near $45 \mathrm{~km}$ and maximum near $35 \mathrm{~km}$, with some variation in the representation in different datasets. Cross-sections of MLS and SABER temperatures (Fig. 8), center panels show a double-peak in the temperatures over Eureka in this region; that it is broader in MLS is likely related to MLS' coarser vertical resolution, and may explain the more pronounced maximum in SABER (in closer agreement with the lidar profile), which has the highest vertical resolution of the satellite instruments. The sharper local minimum in the lidar profile could also be related to its high resolution being able to capture local structure in this region of very strong temperature gradients.

The profiles on 26 February 2006 (Fig. 7) show large variations in stratopause altitude between the instruments. Figure 8 (right panels) shows significant differences in structure between MLS and SABER at Eureka; the analyses (although still not representing the stratopause well at its highest altitudes) have structure more similar to MLS in the region west of Eureka where the stratopause dips, suggesting that the coarser horizontal resolution of SABER may result in undersampling of that transition region. In this region, there are very strong vertical and horizontal temperature gradients as the narrow stratopause tilts sharply downward; thus, small differences in position could very well result in significant changes in stratopause altitude.

The above examples not only detail the dramatic differences in profile structure resulting from the extreme conditions in the three winters, but also show how the details of those meteorological conditions in the region immediately surrounding Eureka may be critical to interpreting temperature measurements and intercomparisons of temperature measurements there. In all three years, but particularly in 2004 and 2006, the very large atmospheric variability around Eureka can lead to real differences in nearly-coincident profiles.

\subsection{MLS Trace Gases at Eureka}

One of the important questions that arises from the disparate conditions in these three extreme winters is how these conditions affect transport in and around the polar vortex. Randall et al. $(2005,2006)$ showed unusually strong descent in the late winters of 2004 and 2006, with mesospheric air de- scending into the unusually strong vortex that reformed after the major SSWs in those years. Model simulations (Siskind et al., 2007) indicate the filtering of gravity waves by the disturbed stratospheric flow responsible for the very high altitude stratopause after the SSW also resulted in enhanced radiative cooling, not only making the upper stratosphere colder than usual and strengthening the redeveloping vortex, but also producing enhanced descent of mesospheric air into the upper stratospheric vortex. Unusual trace gas evolution may also be expected as a result of strong mixing of vortex and extra-vortex air during the SSWs. For measurements at Eureka, its position relative to the vortex also adds to the complexity of observed trace gas evolution. Numerous trace gas measurements were made during the Eureka campaigns Walker et al. 2005; Kerzenmacher et al. 2005; Sung et al. 2007a; Sung et al. 2007b ${ }^{1}$, Frase et al. 2007; Fu et al. 2007, and their interpretation is facilitated by knowledge of the overall patterns of transport in the region. We use timeseries of MLS long-lived trace gas evolution at Eureka to illustrate how transport in the three winters controls trace gas evolution at Eureka.

Figure 9 shows timeseries of the long-lived tracers $\mathrm{CO}$, $\mathrm{H}_{2} \mathrm{O}$ and $\mathrm{N}_{2} \mathrm{O}$ from MLS data coincident with Eureka during the 2004-2005 and 2005-2006 winters. As noted in (Sect. 4.1), the position of the top of the sPV contours gives an indication of the location of the stratopause (Sect. 4.1), while the Eureka crossings of those contours in time show when the stratospheric vortex was over Eureka. The vortex was over Eureka during most of the 2004-2005 winter, and $\mathrm{CO}$ and $\mathrm{H}_{2} \mathrm{O}$ show the signatures of strong, confined descent in the lower mesosphere through midstratosphere through late March (descending high $\mathrm{CO} /$ low $\mathrm{H}_{2} \mathrm{O}$ contours). The vortex moved away from Eureka in early March 2005 at the beginning of the major final warming, but its remnants moved back over Eureka twice later in the month. During those periods, the high $\mathrm{CO}$ in the vortex over Eureka indicates that it had descended from the mesosphere to well below $10 \mathrm{hPa}(\sim 30 \mathrm{~km})$ over the course of the 2004-2005 winter; the peak $\mathrm{H}_{2} \mathrm{O}$ mixing ratio, initially in the upper stratosphere, descended to $\sim 40 \mathrm{hPa}(\sim 22 \mathrm{~km})$. When the vortex was over Eureka during the 2005 campaign, that signature was seen in high $\mathrm{CO}$, high $\mathrm{H}_{2} \mathrm{O}$ below $\sim 10 \mathrm{hPa}(\sim 30 \mathrm{~km})$, and very low $\mathrm{N}_{2} \mathrm{O}$. After $\sim 10$ March, the vortex had broken up above $\sim 3-7 \mathrm{hPa}(\sim 35-40 \mathrm{~km})$ and thus tracer values similar to those typical of midlatitudes were seen, since air from vortex remnants has been diluted by mixing with extravortex air (e.g. Manney et al., 2006a, 2007a).

In contrast, in 2005-2006, the signature of strong descent in $\mathrm{CO}$ and $\mathrm{H}_{2} \mathrm{O}$ is interrupted by the SSW. The disappearance of that signature is not only because the vortex (or its remnant) moves away from Eureka, but also because the nearcomplete break up of the vortex resulted in extensive mixing of midlatitude and vortex air. When the vortex moved back over Eureka in early February (at which point it was reforming only in the upper stratosphere), there is little indication of 


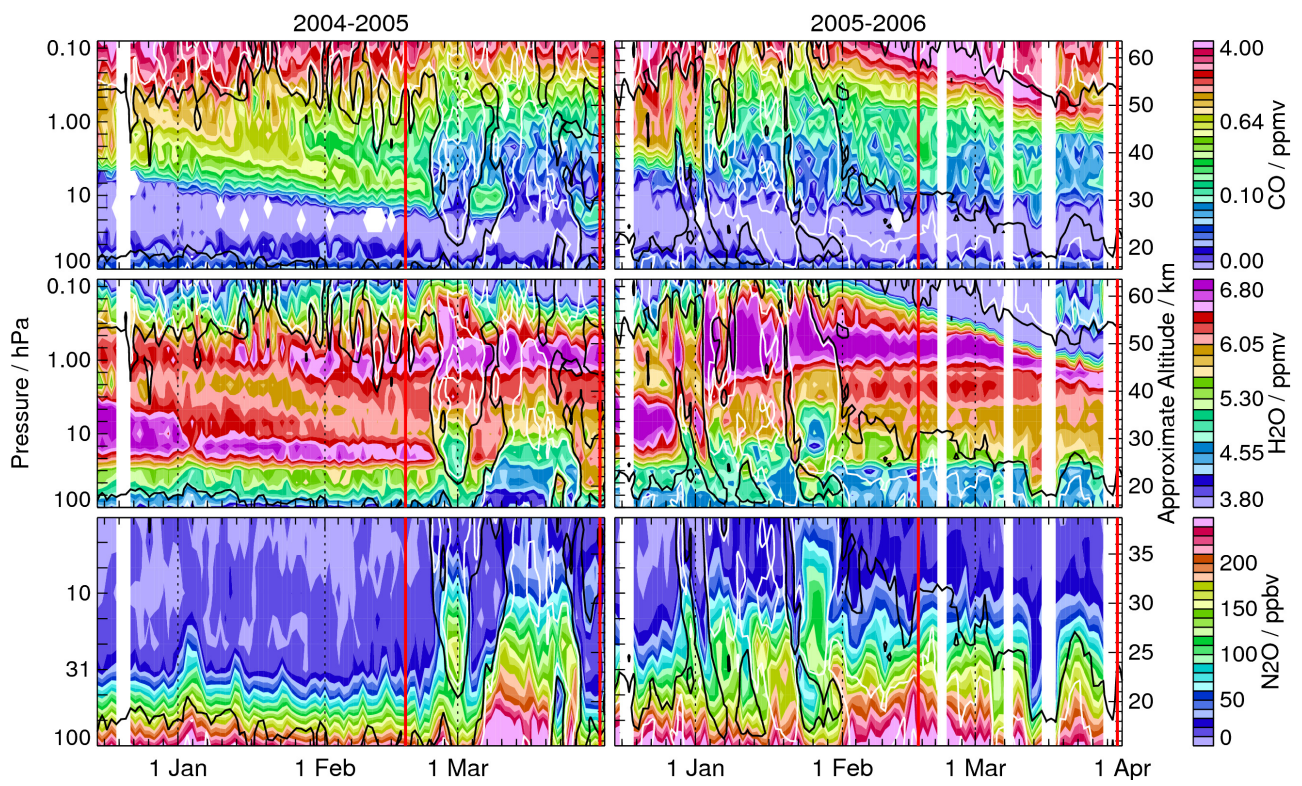

Fig. 9. Timeseries in (left) 2004-2005 and (right) 2005-2006 of trace gas measurements from MLS near Eureka: (top) CO, (center) $\mathrm{H}_{2} \mathrm{O}$ and (bottom) $\mathrm{N}_{2} \mathrm{O}$. Values on each day are averages of all observations coincident (see text) with Eureka on that day. Overlaid contours are sPV in the vortex edge region, with the black contour towards the vortex interior. Vertical red lines show periods of Eureka measurement campaigns. Vertical range for $\mathrm{CO}$ and $\mathrm{H}_{2} \mathrm{O}$ is into the lower mesosphere; vertical range for $\mathrm{N}_{2} \mathrm{O}$ is into the upper stratosphere.

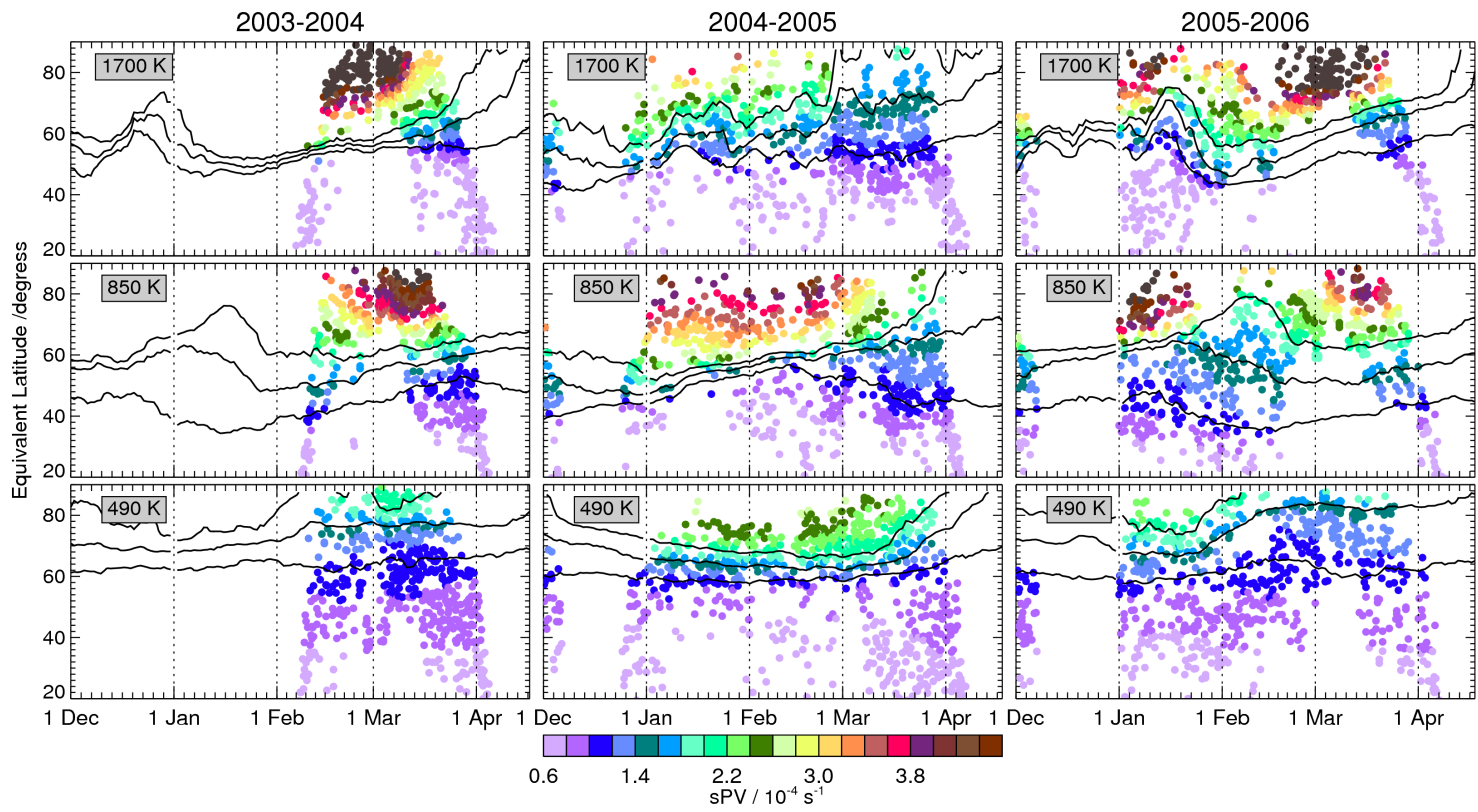

Fig. 10. Timeseries for 1 December through 15 April (left to right) 2003-2004, 2004-2005, and 2005-2006, of sPV (10 ${ }^{-4} \mathrm{~s}^{-1}$ ) from GEOS-4 at ACE observation locations (colors) as a function of EqL. Overlaid contours are GEOS-4 sPV of $1.2,1.6$ and $2.0 \times 10^{-4} \mathrm{~s}^{-1}$.

trace gas values similar to those in the vortex before the SSW. However, near the stratopause, as the vortex redeveloped, there was also strong descent from the lower mesosphere into the stratospheric vortex, in an echo of the behavior typical of the fall vortex development. Consistent with the arguments given above and the simulations of Siskind et al. (2007), this descent is much stronger than that at high altitudes in the
2005 late winter, when the upper stratospheric vortex was weakening and warming. The redeveloping vortex is over Eureka throughout the 2006 campaign, with corresponding evidence of enhanced descent. The lower "vortex edge" SPV contour indicates that the vortex had not redeveloped enough to be well-defined at lower altitudes; the descent of this contour over the course of the campaign, accompanied 
by that of vortex-like trace gas values, reflects the redevelopment of the vortex, while day-to-day variations indicate primarily changes in position of the vortex with respect to Eureka. The lower stratospheric vortex remained very weak and never redeveloped the strong tracer gradients across its edge that were seen before the SSW; thus $\mathrm{N}_{2} \mathrm{O}\left(\mathrm{H}_{2} \mathrm{O}\right)$ below $\sim 20 \mathrm{hPa}(\sim 27 \mathrm{~km})$ during the campaign are considerably higher (lower) than those in the vortex before the warming.

\section{ACE-FTS Meteorological Context and MLS/SABER Comparisons}

ACE-FTS provided measurements covering the high Arctic in February through March 2004, and January through March 2005 and 2006. The ACE observation locations shown in Figs. 1 through 3 (Sect. 3) indicate that ACE sampled both vortex and extra-vortex air on many days. The patterns and extent of vortex and extra-vortex sampling are critical to interpretation of ACE measurements, and depend strongly on the meteorological conditions.

Figure 10 shows sPV at all ACE measurement locations with equivalent latitude (EqL, the latitude that would enclose the same area as a given PV contour, e.g., Butchart and Remsberg (1986)) greater than $20^{\circ} \mathrm{N}$ as a function of EqL and time in the upper $(1700 \mathrm{~K}, \sim 2 \mathrm{hPa})$, middle $(850 \mathrm{~K}$, $\sim 10 \mathrm{hPa}$ ) and lower $(490 \mathrm{~K}, \sim 50 \mathrm{hPa})$ stratosphere, illustrating ACE coverage of the vortex. The overlaid SPV contours are typically (especially in the middle to lower stratosphere) in the region of strong gradients demarking the vortex edge during winter - for example, in January through early to midMarch 2005 at 490 and $850 \mathrm{~K}$ (a period with a strong, cold vortex). In contrast, in 2004 and 2006, the gradients at the higher two values tighten in the middle stratosphere going into the SSWs (until early January 2004, late January 2006) and then weaken dramatically, reflecting the vortex breakdown. In the upper stratosphere $(1700 \mathrm{~K})$, the SSWs are characterized by rapid shrinking of the vortex area (late December 2003, mid-January 2006) with sPV gradients remaining strong, followed immediately by a rapid increase in that area as enhanced radiative cooling leads to reformation of a large, strong vortex. In 2005, and other winters without strong SSWs, the upper stratospheric vortex is never as strong as that after the 2004 and 2006 SSWs, and begins to break down in late February, a few weeks before the breakdown in the middle and lower stratosphere. During each winter, ACE sampling patterns lead to relatively complete coverage of the vortex in the middle stratosphere, except during the vortex breakdown in late January 2006. A significant difference related to the meteorology is seen in early March, when ACE sampled at very high latitudes: in 2005, the vortex is breaking up in the middle stratosphere, and thus very high latitude sampling includes extravortex air, whereas in 2004 and 2006, the vortex has reformed and is relatively polecentered after the SSWs (Fig. 2) so ACE sampled almost entirely well inside the vortex. A similar effect is seen in the upper stratosphere from late February to mid-March 2004, and from mid-February to late March 2006. Upper stratospheric ACE measurements in 2005 do not cover the vortex core region as well as in the more disturbed winters. In the lower stratosphere, ACE measurements typically cover the extravortex and vortex edge regions well, but extend to highest equivalent latitudes (vortex core) only when the vortex is weak and ill-defined after the SSWs in 2004 and 2006.

Comparison of ACE-FTS high-latitude temperatures with those from MLS and SABER at locations coincident with ACE (Fig. 11) demonstrates that the evolution seen at Eureka (Sect. 4.1) is characteristic of the high Arctic. Figure 11 shows timeseries of ACE-FTS temperatures at latitudes above $60^{\circ} \mathrm{N}$ averaged over all measurements for each day, compared with daily averages of coincident MLS and SABER measurements. The top panels show the latitude and number of ACE-FTS profiles included on each day. Except on days with few ACE-FTS measurements, this is similar to a zonal mean with latitude varying from day to day. ACE-FTS captured the main features of temperature evolution during each winter, with a low stratopause after the SSWs in 2004 and 2006 redeveloping at very high altitude, accompanied by an unusually high-altitude coldpoint. The 2005 stratopause remained near $50-60 \mathrm{~km} \sim 0.2-1.0 \mathrm{hPa})$ throughout the winter, with a coldpoint near 15-25 km $(\sim 30$ $100 \mathrm{hPa}$ ). ACE-FTS temperatures show good agreement with MLS and SABER throughout the periods with coincident measurements, with some small biases consistent with those reported by Schwartz et al. (2007) and Sica et al. (2007) in detailed quantitative comparisons for statistical samples.

Because of generally good coverage of the vortex throughout the stratosphere (Fig. 10), "vortex averages" of ACE-FTS data are expected to be representative in January through March, and reflect interannual differences in meteorology. Figure 12 shows ACE-FTS vortex-averaged $\mathrm{CO}$ and $\mathrm{N}_{2} \mathrm{O}$ compared to coincident MLS data. Steady descent is seen in January through March 2005 from the mesosphere to the midstratosphere, with similar (but stronger) descent in January 2006 interrupted by the SSW, then followed by a "replay" with enhanced descent from the mesosphere in February and March 2006, similar to the patterns that were apparent at Eureka (Fig. 9) when the vortex was over it. CO in the middle and upper stratosphere shows the signature of mixing and vortex breakup during the SSW in late January 2006, in the dissipation of very high values characteristic of the vortex as they are mixed with midlatitude air with near-zero $\mathrm{CO}$. In the lower stratosphere in 2005, $\mathrm{N}_{2} \mathrm{O}$ shows the dominant signature of confined descent in the overall downward progression of the contours through early March; after mid-March, when the lower stratospheric vortex is breaking up, large increases in $\mathrm{N}_{2} \mathrm{O}$ indicate not only a signature of mixing, but also the difficulty in defining the vortex edge appropriately at such times (Manney et al., 2007a). In contrast, in 2006, there was an abrupt increase in vortex $\mathrm{N}_{2} \mathrm{O}$ at the time of the $\mathrm{SSW}$, as the vortex broke down; the vortex remained weak 


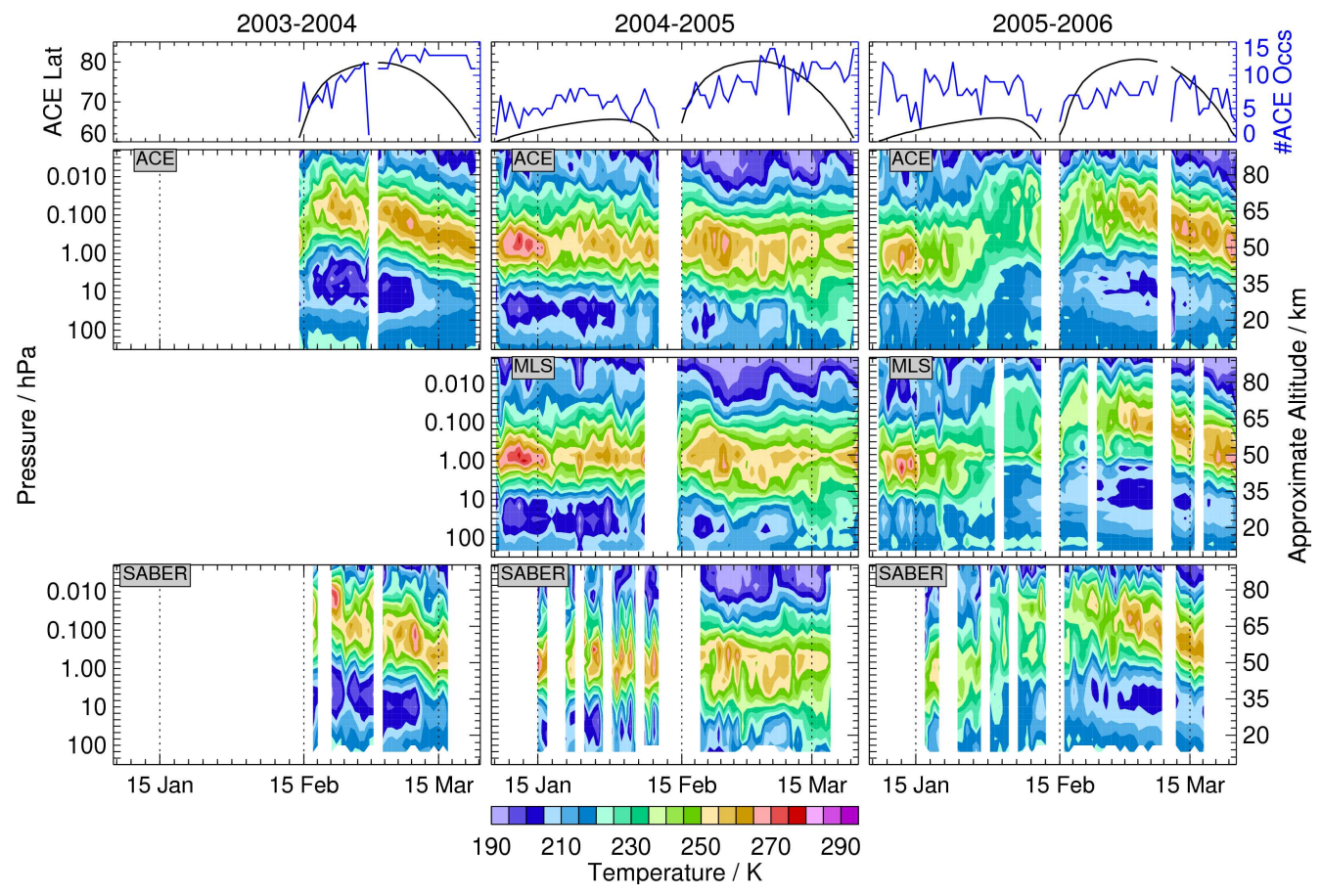

Fig. 11. Timeseries of average temperatures north of $60^{\circ} \mathrm{N}$ (colored panels) from (top to bottom) ACE-FTS, MLS, and SABER. ACE-FTS values are the average of all occultations on each day north of $60^{\circ} \mathrm{N}$; MLS and SABER values are averages of all observations coincident (see text) with the ACE-FTS observations used on each day. Top panels show average latitude of ACE-FTS observations (black), and number of ACE-FTS profiles included (blue) on each day. Time period covered is 5 January through 25 March in (left to right) 2004,2005 and 2006.

and ill-defined for the remainder of the winter, and $\mathrm{N}_{2} \mathrm{O}$ remained relatively constant. ACE-FTS and coincident MLS $\mathrm{CO}$ and $\mathrm{N}_{2} \mathrm{O}$ agree quite well, consistent with more quantitative comparisons (Clerbaux et al., 2007; Lambert et al., 2007; Manney et al., 2007a; Pumphrey et al., 2007; Strong et al., 2007).

\section{Summary and conclusions}

The winters of the first three years of ACE observations and Canadian Arctic ACE Validation Campaigns at Eureka ("Eureka campaigns") represented the two extremes of Arctic winter variability. New satellite datasets available during these winters from ACE-FTS, MLS, and SABER provide an unprecedented wealth of temperature and trace gas data covering the upper troposphere through the mesosphere. We use ACE-FTS, MLS and SABER satellite data, along with meteorological analyses and high-resolution ground-based temperature data, to detail the dramatic contrasts in the meteorology during extremely cold and extremely disturbed Arctic winters, and relate these differences to variations in transport and chemistry. We focus on conditions over Eureka and on the effects of the extreme meteorology on ACE sampling and interpretation of ACE-FTS data; these results provide context for interpretation of validation results presented in other papers in this special issue.
There were unusually strong and prolonged major stratospheric sudden warmings (SSWs) in January in both 2004 and 2006. Temperature and vortex evolution was very similar in the two years, with the vortex breaking down throughout the stratosphere, reforming quickly in the upper stratosphere while remaining weak in the middle and (especially) lower stratosphere. In both years, the satellite data show that the stratopause (temperature maximum) reformed at very high altitude (near $80 \mathrm{~km}$ ) during recovery from the SSWs. Parallel changes in tropopause and stratopause demonstrate troposphere-stratosphere-mesosphere coupling. Assimilated meteorological analyses do not capture the extreme stratopause variations. The 2004 and 2006 Eureka campaigns were during the recovery from the SSWs, with the redeveloping vortex over Eureka. Consistent with this, 2004 and 2006 temperatures at Eureka show a sharp, shallow, low tropopause near $400 \mathrm{hPa}$, a local temperature maximum near $200 \mathrm{hPa}$, decreasing temperatures up to $\sim 10-3 \mathrm{hPa}$ (where temperatures were as much as $\sim 25 \mathrm{~K}$ below tropopause values in February to early March), and stratopause above $0.01 \mathrm{hPa}$, near $75-80 \mathrm{~km}$. The strong, symmetric vortex following the SSWs resulted in ACE measurements that were entirely inside the vortex in the middle and upper stratosphere in mid-February through mid-March during these years. 


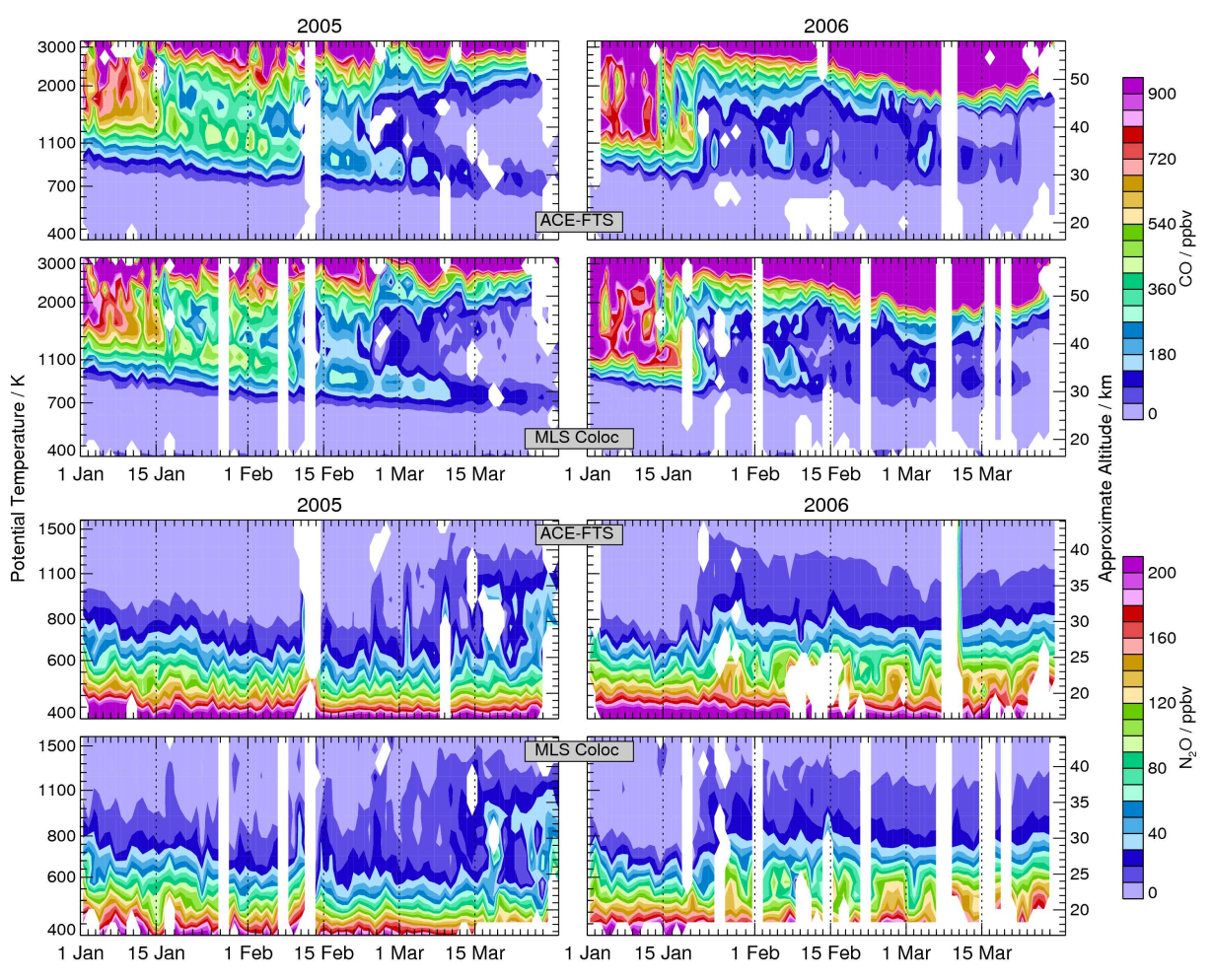

Fig. 12. Timeseries in (left) 2005 and (right) 2006 of (top set) $\mathrm{CO}$ and (bottom set) $\mathrm{N}_{2} \mathrm{O}$ averaged within the vortex (defined by $1.4 \times 10^{-4} \mathrm{~s}^{-1}$ contour) from ACE-FTS (top) and from MLS observations coincident with ACE (bottom). Vertical range for CO is from 400 through $3200 \mathrm{~K}$; for $\mathrm{N}_{2} \mathrm{O}$, from 400 through $1600 \mathrm{~K}$.

In contrast, the 2005 winter was the coldest on record in the lower stratosphere, but with an early final warming/vortex breakup in mid-March; the upper stratospheric vortex began weakening and warming by February; ACE sampling of the upper stratospheric vortex core was less complete than that of the strong upper stratospheric vortices in 2004 and 2006. At the start of the 2005 Eureka campaign, through early March 2005, the vortex was over Eureka, and temperature structure was typical of a cold winter vortex, with a weak tropopause near $200-300 \mathrm{hPa}$, coldpoint between $\sim 100$ and $\sim 30 \mathrm{hPa}$, and the stratopause near $0.5-$ $0.1 \mathrm{hPa}$. Upper stratospheric temperatures over Eureka were up to $\sim 50 \mathrm{~K}$ lower in 2004 and 2006 (when a strong, cold vortex reformed after the SSW) than in 2005 (when the upper stratospheric vortex was already breaking down), while middle and lower stratospheric temperatures were up to $\sim 20 \mathrm{~K}$ higher in 2004 and 2006 than in 2005.

ACE-FTS and coincident MLS and SABER measurements representing average high-latitude conditions reflect similar temperature structure and evolution to that seen at Eureka in all three winters. Temperature profiles from the Eureka lidar show very good agreement with coincident MLS, ACE-FTS and SABER measurements up to $50-60 \mathrm{~km}$, with most differences in small vertical-scale structure consistent with the changing meteorological conditions around Eureka and the instruments' sampling patterns and resolution. ACEFTS daily average high-latitude temperatures agree well with coincident MLS and SABER daily averages.

MLS trace gas distributions over Eureka highlight the effects of differing vortex conditions on transport and singlestation sampling. Consistent with the strong, cold upper stratospheric vortex and the enhanced radiative cooling driving its redevelopment after the 2004 and 2006 SSWs, MLS $\mathrm{CO}$ and $\mathrm{H}_{2} \mathrm{O}$ measurements show enhanced vortex descent over Eureka in 2006 compared to that in 2005 when the upper stratospheric vortex (and associated descent) was already weakening. Since the vortex was over Eureka during the 2006 campaign, whereas it was breaking up and moving away from Eureka during the 2005 campaign, MLS observed lower (higher) $\mathrm{H}_{2} \mathrm{O}$ and $\mathrm{CO}\left(\mathrm{N}_{2} \mathrm{O}\right)$ near Eureka in 2005 than in 2006 in and above the middle stratosphere. Since the lower stratospheric vortex was warm and ill-defined in 2006, but over Eureka and still cold at the start of the 2005 campaign, $\mathrm{N}_{2} \mathrm{O}\left(\mathrm{H}_{2} \mathrm{O}\right)$ at Eureka was low (high) in late February 2005 compared to the same time in 2006. ACE-FTS vortex-averaged tracers, compared with coincident MLS values, show similar patterns of vortex transport.

The ACE-FTS, MLS and SABER datasets, along with high-resolution temperatures recorded at Eureka, during the 2003-2004, 2004-2005 and 2005-2006 Arctic winters have 
allowed us to compare in detail the meteorology during these disparate winters, to demonstrate how these conditions affected transport, and to provide a meteorological context for interpretation of ACE-FTS measurements and those taken during the Canadian Arctic ACE Validation Campaigns.

Acknowledgements. We thank the MLS Science Team, especially L. Froidevaux, R. P. Thurstans, R. Fuller, B. W. Knosp, B. J. Mills, D. T. Cuddy, C. Vuu, A. Mousessian, P. A. Wagner, and X. Sabounchi, and the ACE Science Team, especially S. McLeod, R. Skelton, and R. Hughes, for their continuing support and assistance. Thanks to GMAO and S. Pawson for GEOS data and advice on their usage and ECMWF for their products shown here. Research at the Jet Propulsion Laboratory, California Institute of Technology, is done under contract with the National Aeronautics and Space Administration. Funding for the ACE mission was provided primarily by the Canadian Space Agency (CSA) and the Natural Sciences and Engineering Research Council of Canada (NSERC). The Canadian Arctic ACE Validation campaign project has been supported by CSA, Environment Canada (EC), NSERC, the Northern Scientific Training Program and the Centre for Global Change Science at the University of Toronto. Logistical and on-site technical support for the 2006 campaign was provided by the Canadian Network for the Detection of Atmospheric Change (CANDAC). CANDAC and PEARL are funded by the Canadian Foundation for Climate and Atmospheric Sciences, NSERC, the Canadian Foundation for Innovation, the Ontario Innovation Trust and the Atlantic Innovation Fund/Nova Scotia Research Innovation Trust.

Edited by: A. Richter

\section{References}

Bernath, B. F., McElroy, C. T., Abrams, M. C., et al.: Atmospheric Chemistry Experiment (ACE): mission overview, Geophys. Res. Lett., 32, L15S01, doi:10.1029/2005GL022386, 2005.

Bloom, S. C., McElroy, C. T., Abrams, M. C., et al.: The Goddard Earth Observing Data Assimilation System, GEOS DAS Version 4.0.3: Documentation and Validation, Tech. Rep. 104606 V26, NASA, 2005.

Boone, C. D., Nassar, R., Walker, K. A., Rochon, Y., McLeod, S. D., Rinsland, C. P., and Bernath, P. F.: Retrievals for the Atmospheric Chemistry Experiment Fourier-Transform Spectrometer, Appl. Opt., 44, 7218-7231, 2005.

Braathen, G., Grunow, K., Kivi, R., Kyrö, E., Raffalski, U., Kopp, G., Urban, J., Hochschild, G., Goutail, F., Manney, G. L., Rösevall, J., and Murtagh, D.: Joint WMO/EU Arctic ozone bulletin, winter/spring summary, Tech. Rep. 2006-1, World Meteorological Organization/European Ozone Research Coordinating Unit, available at http://www.wmo.int/pages/prog/arep/gaw/ ozone/index.html, 2006.

Butchart, N. and Remsberg, E. E.: The area of the stratospheric polar vortex as a diagnostic for tracer transport on an isentropic surface, J. Atmos. Sci., 43, 1319-1339, 1986.

Carswell, A. I., Donovan, D. P., Bird, J. C., Duck, T. J., Pal, S. R., and Whiteway, J. A.: Measurements at the Eureka Arctic NDSC station with a Raman DIAL system, in: Advances in atmospheric remote sensing with lidar, edited by: Ansmann, A. and Neuber, R., 521-524, Springer-Verlag, Berlin, 1996.

Clerbaux, C., Coheur, P.-F., Hurtmans, D., Barret, B., Carleer, M., Semeniuk, K., McConnell, J. C., Boone, C., and Bernath, P.: Carbon monoxide distribution from the ACE-FTS solar occultation measurements, Geophys. Res. Lett., 32, L16S01, doi:10.1029/2005GL022394, 2005.

Clerbaux, C., George, M., Turquety, S., et al.: CO measurements from the ACE-FTS satellite instrument: data analysis and validation using ground-based, airborne and spaceborne observations, Atmos. Chem. Phys. Discuss., 7, 15 277-15 340, 2007.

Duck, T. J. and Greene, M. D.: High Arctic observations of mesospheric inversion layers, Geophys. Res. Lett., 31, L02105, doi:10.1029/2003GL018481, 2004.

Dunkerton, T. J. and Delisi, D. P.: Evolution of potential vorticity in the winter stratosphere of January-February 1979, J. Geophys. Res., 91, 1199-1208, 1986.

Fraser, A., Goutail, F., Strong, K., and Others: UV-Visible measurements of ozone and $\mathrm{NO}_{2}$ at PEARL, Eureka, Nunavut 2004 2007, Atmos. Chem. Phys. Discuss., 7, 16 283-16347, 2007.

Froidevaux, L., Livesey, N. J., Read, W. G., et al.: Early Validation analyses of atmospheric profiles from EOS MLS on the Aura Satellite, IEEE Trans. Geosci. Remote Sens., 44, 1106-1121, 2006.

Fussen, D., Vanhellemont, F., Dodion, J., Bingen, C., Walker, K. A., Boone, C. D., McLeod, S. D., and Bernath, P. F.: Initial intercomparison of ozone and nitrogen dioxide number density profiles retrieved by the ACE-FTS and GOMOS occultation experiments, Geophys. Res. Lett., 32, L16S02, doi:10.1029/2005GL022468, 2005.

Garcia, R. R. and Boville, B. A.: "Downward control" of the mean meridional circulation and temperature distribution of the polar winter stratosphere, J. Atmos. Sci., 51, 2238-2245, 1994.

Hauchecorne, A. and Chanin, M. L.: Density and temperature profiles obtained by lidar between 35 and $70 \mathrm{~km}$, Geophys. Res. Lett., 8, 565-569, 1980.

Highwood, E. J. and Berrisford, P.: Properties of the Arctic tropopause, Q. J. Roy. Meteorol. Soc., 126, 1515-1532, 2000.

Hitchman, M. H., Gille, J. C., Rodgers, C. D., and Brasseur, G.: The separated polar stratopause: A gravity wave driven climatological feature, J. Atmos. Sci., 46, 410-422, 1989.

Hoffmann, P., Singer, W., Keuer, D., Hocking, W. K., Kunze, M., and Murayama, Y.: Latitudinal and longitudinal variability of mesospheric winds and temperatures during stratospheric warming events, J. Atmos. Sol.-Ter. Phys., 69, 2355-2366,, 2007.

Jin, J. J., Semeniuk, K., Jonsson, A. I., et al.: Co-located ACEFTS and Odin/SMR stratospheric-mesospheric CO 2004 measurements and comparison with a GCM, Geophys. Res. Lett., 32, L15S03, doi:10.1029/2005GL022 433, 2005.

Kerzenmacher, T. E., Walker, K. A., Strong, K., et al.: Measurements of $\mathrm{O}_{3}, \mathrm{NO}_{2}$ and Temperature During the 2004 Canadian Arctic ACE Validation Campaign, Geophys. Res. Lett., 32, L16S07, doi:10.1029/2005GL023032, 2005.

Kutepov, A., Feofilov, A., Marshall, B., Gordley, L., Pesnell, W., Goldberg, R., and Russell III, J.: SABER temperature observations in the summer polar mesosphere and lower thermosphere: Importance of accounting for the $\mathrm{CO}_{2} \mathrm{v}_{2}$ quanta $\mathrm{V}-\mathrm{V}$ exchange, Geophys. Res. Lett., 33, L21809, doi:10.1029/2006GL026591, 2006. 
Labitzke, K.: Temperature changes in the mesosphere and stratosphere connected with circulation changes in winter, J. Atmos. Sci., 29, 756-766, 1972.

Lambert, A., Read, W. G., Livesey, N. J., et al.: Validation of the Aura Microwave Limb Sounder stratospheric water vapor and nitrous oxide measurements, J. Geophys. Res., J. Geophys. Res., 112, D24S36, doi:10.1029/2007JD008724, 2007.

Livesey, N. J., Read, W. J., Filipiak, M. J., et al.: Validation of Aura Microwave Limb Sounder $\mathrm{O}_{3}$ and $\mathrm{CO}$ observations in the upper troposphere and lower stratosphere, J. Geophys. Res., in press, 2007. Available at http://mls.jpl.nasa.gov.,2007.

Mahieu, E., Zander, R., Duchatelet, P., et al.: Comparisons between ACE-FTS and ground-based measurements of stratospheric $\mathrm{HCl}$ and $\mathrm{ClONO}_{2}$ loadings at northern latitudes, Geophys. Res. Lett., 32, L15S08, doi:10.1029/2005GL022396, 2005.

Manney, G. L., Zurek, R. W., O'Neill, A., and Swinbank, R.: On the motion of air through the stratospheric polar vortex, J. Atmos. Sci., 51, 2973-2994, 1994.

Manney, G. L., Krüger, K., Sabutis, J. L., Sena, S. A., and Pawson, S.: The remarkable 2003-2004 winter and other recent warm winters in the Arctic stratosphere since the late 1990s, J. Geophys. Res., 110, D04107, doi:10.1029/2004JD005367, 2005.

Manney, G. L., Livesey, N. J., Jimenez, C. J., Pumphrey, H. C., Santee, M. L., MacKenzie, I. A., Froidevaux, L., and Waters, J. W.: EOS MLS observations of "frozen-in" anticyclonic air in Arctic summer, Geophys. Res. Lett., 33, L06810, doi:10.1029/2005GL025418, 2006a.

Manney, G. L., Santee, M. L., Froidevaux, L., Hoppel, K., Livesey, N. J., and Waters, J. W.: EOS MLS observations of ozone loss in the 2004-2005 Arctic winter, Geophys. Res. Lett., 33, L04802, doi:10.1029/2005GL024494, 2006b.

Manney, G. L., Daffer, W. H., Zawodny, J. M., et al.: Solar Occultation Satellite Data and Derived Meteorological Products: Sampling Issues and Comparisons with Aura MLS, J. Geophys. Res., 112, D24S31, doi:10.1029/2007JD008709, 2007.

McHugh, M., Magill, B., Walker, K. A., Boone, C. D., Bernath, P. F., and Russell III, J. M.: Comparison of atmospheric retrievals from ACE and HALOE, Geophys. Res. Lett., 32, L15S10, doi:10.1029/2005GL022403, 2005.

Mlynczak, M. and Russell, J.: An overview of the SABER experiment for the TIMED mission, NASA Langley Research Center, Optical Remote Sensing of the Atmosphere, 2, 5-7, 1995.

Petelina, S. V., Llewellyn, E. J., Walker, K. A., Degenstein, D. A., Boone, C. D., Bernath, P. F., Haley, C. S., von Savigny, C., Lloyd, N. D., and Gattinger, R. L.: Validation of ACE-FTS stratospheric ozone profiles against Odin/OSIRIS measurements, Geophys. Res. Lett., 32, L15S06, doi:10.1029/2005GL022377, 2005.

Pumphrey, H. C., Filipiak, M. J., Livesey, N. J., et al.: Validation of the Aura Microwave Limb Sounder stratospheric and mesospheric CO measurements, J. Geophys. Res., 112, D24S38, doi:10.1029/2007JD008723, 2007.

Randall, C. E., Harvey, V. L., Singleton, C. S., Bernath, P. F., Boone, C. D., and Kozyra, J. U.: Enhanced $\mathrm{NO}_{\mathrm{x}}$ in 2006 linked to strong upper stratospheric Arctic vortex, Geophys. Res. Lett., 33, L18811, doi:10.1029/2006GL027160, 2006.

Randall, C. E., Harvey, V. L., Manney, G. L., et al.: Stratospheric effects of energetic particle precipitation in 2003-2004, Geophys. Res. Lett., 32, L05802, doi:10.1029/2004GL022003, 2005.

Reichler, T., Dameris, M., and Sausen, R.: Determining the tropopause height from gridded data, Geophys. Res. Lett., 30, 2042, doi:10.1029/2003GL018240, 2003.

Reinecker, M. M., Suarez, M. J., Todling, R., et al.: The GEOS5 Data Assimilation System: A Documentation of GEOS-5.0, Tech. Rep. 104606 V27, NASA, 2007.

Remsberg, E. E., Lingenfelser, G., Harvey, V. L., Grose, W., III, J. R., Mlynczak, M., Gordley, L., and Marshall, B. T.: On the verification of the quality of SABER temperature, geopotential height, and wind fields by comparison with Met Office assimilated anylyses, J. Geophys. Res., 108, 4628, doi:10.1029/2003JD003720, 2003.

Remsberg, E. E., Deaver, L., Wells, J., et al.: An assessment of the quality of HALOE temperature profiles in the mesosphere based on comparisons with Rayleigh backscatter lidar and inflatable falling sphere measurements, J. Geophys. Res., 107, 4447, doi:10.1029/2001JD001521, 2002.

Schoeberl, M. R.: Extratropical stratosphere-troposphere mass exchange, J. Geophys. Res., 109, D13303, doi:10.1029/2004JD004525, 2004.

Schwartz, M. J., Lambert, A., Manney, G. L., et al.: Validation of the Aura Microwave Limb Sounder temperature and geopotential height measurements, J. Geophys. Res., in press, 2007. Available at http://mls.jpl.nasa.gov, 2007.

Sica, R. J., Izawa, M., Petelina, S. V., et al.: Validation of ACE temperature using ground-based and space-based meassurements, Atmos. Chem. Phys., 8, 35-62, 2008.

Simmons, A. J., Hortal, M., Kelly, G., McNally, A., Untch, A., and Uppala, S.: ECMWF analyses and forecasts of stratospheric winter polar vortex break-up: September 2002 in the southern hemisphere and related events, J. Atmos. Sci., 62, 668-689, 2005

Siskind, D. E., Eckermann, S. D., Coy, L., and McCormack, J. P.: On recent interannual variability of the Arctic winter mesosphere: Implications for tracer descent, Geophys. Res. Lett., 34, L09806, doi:10.1029/2007GL029293, 2007.

Strong, K., Wolff, M. A., Kerzenmacher, T. E., et al.: Validation of ACE-FTS $\mathrm{N}_{2} \mathrm{O}$ measurements, Atmos. Chem. Phys. Discuss., accepted, 2007.

Sung, K., Skelton, R., Walker, K. A., Boone, C. D., Fu, D., and Bernath, P. F.: $\mathrm{N}_{2} \mathrm{O}$ and $\mathrm{O}_{3}$ Arctic column amounts from PARISIR observations: Retrievals, characterization and error analysis, J. Quant. Spectrosc. Ra. , 107 (3), 385-406, Oct 2007 a.

Untch, A., Miller, M., Hortal, M., Buizza, R., and Janssen, P.: Towards a global meso-scale model: The high resolution system T799L91 and T399L62 EPS, ECMWF Newsletter, 108, 6-13, 2006.

Walker, K. A., Randall, C. E., Trepte, C. R., Boone, C. D., and Bernath, P. F.: Initial validation comparisons for the Atmospheric Chemistry Experiment (ACE), Geophys. Res. Lett., 32, L16S04, doi:10.1029/2005GL022388, 2005.

Waters, J. W., Froidevaux, L., Harwood, R. S., et al.: The Earth Observing System Microwave Limb Sounder (EOS MLS) on the Aura satellite, IEEE Trans. Geosci. Remote Sens., 44, 10751092, 2006.

WMO: Scientific assessment of stratospheric ozone depletion: 2006, U. N. Environ. Program, Geneva, Switzerland, 2007.

Wu, W.-S., Purser, R. J., and Parish, D. F.: Three-dimensional variational analyses with spatially inhomogeneous covariances, Mon. Weather Rev., 130, 2905-2916, 2002. 